PNL-6677

UC-70

\title{
Soil Erosion Rates from Mixed Soil and Gravel Surfaces in a Wind Tunnel: A Preliminary Report
}

M. W. Ligotke

December 1988

Prepared for the U.S. Department of Energy under Contract DE-AC06-76RLO 1830

Pacific Northwest Laboratory Operated for the U.S. Department of Energy by Battelle Memorial Institute 


\title{
DISCLAIMER
}

This report was prepared as an account of work sponsored by an agency of the United States Government. Neither the United States Government nor any agency thereof, nor Battelle Memorial Institute, nor any or their employees, makes any warranty, expressed or implied, or assumes any legal liability or responsibility for the accuracy, completeness, or usefulness of any information, apparatus, product, or process disclosed, or represents that its use would not infringe privately owned rights. Reference herein to any specific commercial product, process, or service by trade name, trademark, manufacturer, or otherwise does not necessarily constitute or imply its endorsement, recommendation, or favoring by the United States Government or any agency thereof, or Battelle Memorial Institute. The views and opinions of authors expressed herein do not necessarily state or reflect those of the United States Government or any agency thereof.

\author{
PACIFIC NORTHWEST LABORATORY \\ operated by \\ BATTELLE MEMORIAL INSTITUTE \\ for the \\ UNITED STATES DEPARTMENT OF ENERGY \\ under Contract DE-AC06-76RLO 1830
}

\begin{tabular}{|c|c|}
\hline \multicolumn{2}{|c|}{ Printed in the United States of America } \\
\hline \multicolumn{2}{|c|}{ Available from } \\
\hline \multicolumn{2}{|c|}{ National Technical Information Service } \\
\hline \multicolumn{2}{|c|}{ United States Department of Commerce } \\
\hline \multicolumn{2}{|c|}{5285 Port Royal Road } \\
\hline \multicolumn{2}{|c|}{ Sprongfield, Virginia 22161} \\
\hline \multicolumn{2}{|c|}{ NIIS Price Codes } \\
\hline \multicolumn{2}{|c|}{ Mic rofiche A01 } \\
\hline \multicolumn{2}{|c|}{ Printed Copy } \\
\hline & Price \\
\hline Pages & Codes \\
\hline $001-025$ & $\mathrm{~A} 02$ \\
\hline 026050 & $\mathrm{~A} 03$ \\
\hline $051-075$ & A04 \\
\hline 076.100 & A05 \\
\hline $101-125$ & $A 06$ \\
\hline $126-150$ & $\mathrm{~A} 07$ \\
\hline $151 \cdot 175$ & $A 06$ \\
\hline $176-200$ & A09 \\
\hline 201.225 & A10 \\
\hline $226-250$ & A11 \\
\hline $251-275$ & A12 \\
\hline $276-300$ & A.13 \\
\hline
\end{tabular}


Soil Erosion Rates from Mixed Soil and Gravel Surfaces in a Wind Tunnel: A Preliminary Report

M. W. Ligotke

December 1988

Prepared for the U.S. Department of Energy under Contract DE-AC06-76RLO 1830

Pacific Northwest Laboratory

Richland, Washington 99352 



\section{SUMMARY}

Tests of wind erosion were performed in a controlled-environment wind tunnel to support the development of natural-material protective barriers for long-term isolation of radioactive waste. Barrier performance standards currently being developed for internal and external barner performance are expected to mandate a surface layer that is resistant to wind erosion. The purpose of this study was to initiate a series of tests to determine suitable soil and gravel mixtures for such a barrier and to test worst-case surface layer conditions under the influence of high wind speeds.

Six mixed soil and gravel surfaces were prepared, weathered to represent natural wind-blown desert areas, and subjected to controlled wind erosion forces in a wind tunnel. The applied erosive forces, including surface shear forces, were characterized to provide a means of relating wind tunnel results with actual field conditions. Soil particle losses from the surfaces caused by suspension, saltation, and surface creep were monitored by aerosol sample probes and mass balance measurements.

Gravel size influenced the resistance of surfaces to wind erosion. Small-particle gravel $(0.7-\mathrm{cm}$ dia) provided better wind erosion control at wind speeds to $20 \mathrm{~m} / \mathrm{s}$ (45 mph) than did large-particle gravel (1.6-cm dia). Except for the large-particle test case at the highest wind speed, surfaces gradually hardened during exposure to sustained wind forces and formed protective crusts that resulted in decreased rates of soil erosion. The reason no protective crust developed during high wind speed tests of the surface containing large-particle gravel was likely because of large wind shear forces deflected by the gravel to the air/soil interface.

Wind tunnel experiments of surface configuration and resistance to deflation should be continued to provide a stable surface for the protective barnier. Wind tunnel tests are planned that will increase the number of surface types tested and investigate the effects of natural surface crusts, vegetative cover, plant roots (diffuse and deep root structures), burrowing animals, and other factors such as structures of the microterrain. The influence of turbulence and peak wind gusts should also be addressed. Studies are also needed to investigate the effects of deposition of windborne materials (primarily sand) to the barrier surface and the potential formation of large-scale wind erosion structures such as sand dunes and blowouts. 


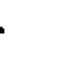




\section{ACKNOWLEDGMENTS}

This work was funded by the U.S. Department of Energy through the Westinghouse Hanford Waste Management Program Office. Richard A. Carlson prepared the test plan that was the basis for the completed tests and contributed to early experiments. Donald C. Klopfer provided valuable support during the entire series of experiments. Dominic A. Cataldo provided guidance and useful suggestions. Conversations and technical seminars involving all members of the protective barrier development team were valuable in defining the current and future direction of this project. Special thanks to team members involved with the review of early drafts of this document. Suggestions by Glendon W. Gee and W. Jody Waugh were especially useful and contributed to the correct interpretation of the results. 



\section{CONTENTS}

SUMMARY .................... . iii

ACKNOWLEDGMENTS ..................

1.0 INTRODUCTION . . . . . . . . . . . . . . . . . . . 1.1

2.0 BACKGROUND . . . . . . . . . . . . . . . . . . . . . 2.1

2.1 SURFACE LAYER CHARACTERISTICS . . . . . . . . . . . . . 2.1

2.2 WIND EROSION . . . . . . . . . . . . . . . . . . 2.3

2.3 EFFECTS OF WIND EROSION ON BARRIER SURFACES . . . . . . 2.4

2.4 WIND TUNNEL MODELING . . . . . . . . . . . . . . . . 2.5

3.0 MATERIALS AND METHODS . . . . . . . . . . . . . . . . 3.1

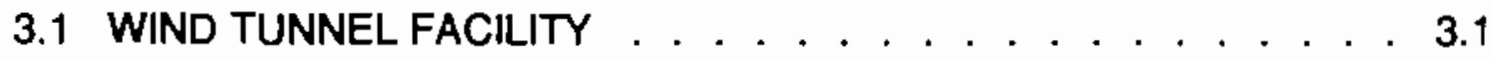

3.2 SOIL AND GRAVEL CHARACTERISTICS . . . . . . . . . . . . 3.3

3.3 PREPARATION OF TEST SURFACES . . . . . . . . . . . . 3.5

3.3.1 Soil, Gravel, and Tracer Mixing Procedures . . . . . . . . 3.6

3.3.2 Test Trays . . . . . . . . . . . . . . . . . . . . . . . 3.6

3.3.3 Surface Weathering . . . . . . . . . . . . . . . . . . . 3.8

3.3.4 Boundary Layer Surface . . . . . . . . . . . . . . . . . 3.10

3.4 TEST PROCEDURES . . . . . . . . . . . . . . . . . . . . . . 3.11

3.4.1 Configuration of Test Surface . . . . . . . . . . 3.11

3.4.2 Description of Test Sequence. . . . . . . . . . . . . . 3.12

3.5 MEASUREMENTS. . . . . . . . . . . . . . . . . . . . . 3.13

3.5.1 Mean Air Velocity . . . . . . . . . . . . . . . . . . . 3.13

3.5.2 Air Flow Boundary Layer . . . . . . . . . . . . . . . . . 3.13

3.5.3 Threshold Velocity and Laser Particle Analyzer . . . . . . . 3.14

3.5.4 Isokinetic Aerosol Measurement. . . . . . . . . . . . . . . 3.14 
3.5.5 Sample Mass and Tracer Material . . . . . . . . . . 3.15

3.5.6 Bulk Tray Mass . . . . . . . . . . . . . . . . . . . . . . 3.16

3.5.7 Soil Moisture Content . . . . . . . . . . . . . . . . . . 3.17

3.6 INSTRUMENT OPERATION . . . . . . . . . . . . . . 3.17

4.0 RESULTS AND DISCUSSION . . . . . . . . . . . . . . . . 4.1

4.1 BOUNDARY LAYERS, SURFACE ROUGHNESS, AND

FRICTION VELOCITY . . . . . . . . . . . . . . . . . . . . . . 4.1

4.2 TESTS AND SOIL MOISTURE CONTENT . . . . . . . . . . 4.9

4.3 FLUORESCENT TRACER . . . . . . . . . . . . . . . . . . . 4.11

4.4 SAMPLING PROBE LOSSES. . . . . . . . . . . . . . . . . 4.12

4.5 PARTICLE CONCENTRATION PROFILES . . . . . . . . . . . . . 4.12

4.6 MASS BALANCE: AEROSOL SAMPLES VS. ACTUAL

SURFACE MASS LOSS . . . . . . . . . . . . . . . . . . . 4.14

4.7 DEFLATION AND SOIL PARTICLE SUSPENSION RATES. . . . . 4.16

5.0 CONCLUSIONS AND RECOMMENDATIONS . . . . . . . . . 5.1

6.0 REFERENCES . . . . . . . . . . . . . . . . . 6.1 


\section{EIGURES}

2.1 Conceptual Design of Multilayer Protective Barner. . . . . . . . . . . 2.2

3.1 Orthographic Projection of the PNL Aerosol Wind Tunnel Research Facility . . . . . . . . . . . . . . . . . . . 3.2

3.2. The McGee Ranch and Area 1 on the Hanford Site. . . . . . . . . . . 3.4

3.3 Particle Size Distributions of Pea and 3/4-in. Source Gravels for Wind Tunnel Surface Stability Tests. . . . . . . . . . . . . . . . . . . . 3.5

3.4 Schematic View of Test Trays and Support Ring. . . . . . . . . . . . . 3.7

3.5 Cross-Sectional View of Wind Tunnel Test Section Showing Test and Boundary Layer (Fixed) Surfaces, Air Flow Direction and Boundary Layers, and Aerosol Sampling Probes . . . . . . . . . . . 3.12

3.6 Wind Tunnel Mean Wind Speed Calibrations . . . . . . . . . . . . . 3.19

3.7 Flowmeter Calibration for Aerosol Sampler . . . . . . . . . . . . . . 3.20

3.8 Pressure Gage Calibration for Aerosol Sampler . . . . . . . . . . . . 3.20

4.1 Horizontal Velocity Profile Across the Width of Test Surfaces . . . . . . 4.2

4.2 Standard and Normalized Boundary Layer Profiles over the Aluminum Plate Surface, Upwind of the Test Surface . . . . . . . . . 4.3

4.3 Standard and Nomalized Boundary Layer Profiles over the Fixed Boundary Layer Surface, Upwind of the Test Surface. . . . . . . . . . . 4.4

4.4 Standard and Normalized Boundary Layer Profiles Over the Test Surface. . . . . . . . . . . . . . . . . 4.5

4.5 Boundary Layers over the Aluminum Plate Surface, Plotted for the Determination of Surface Roughness and Friction Velocities.

4.6 Boundary Layers over the Fixed Boundary Layer Surface, Plotted for the Determination of Surface Roughness and Friction Velocities . . . 4.8

4.7 Boundary Layers over the Test Surface, Plotted for the Determination of Surface Roughness and Friction Velocities

4.8 Calibration of Fluorescent Tracer Versus Mass Collected in Aerosol Samples 
4.9 Normalized Suspended Soil Particle Vertical Concentration Profiles over Test Surfaces at 10 and $20 \mathrm{~m} / \mathrm{s}$. . . . . . . . . . . . . . . . . 4.13

4.10 Change-in-Mass of Test Surface Versus Mass of Suspended Soil Particles Collected in Isokinetic Aerosol Samples

4.11 Rates of Deflation for Weathered Surfaces Initially (i), and After 500 to $1,500 \mathrm{~min}(f)$ Exposure to Steady Wind Speeds of 5,10 , and $20 \mathrm{~m} / \mathrm{s}$.

4.12 Rates of Surface Deflation Versus Wind Speed Based on Aerosol (Top Plot) and Bulk Tray Mass (bottom plot) Data . . . . . . . . . . . 4.19

4.13 Surface Deflation Rates Versus Time of Exposure to Steady Wind Speeds of 5,10 , and $20 \mathrm{~m} / \mathrm{s}$ 


\section{IABLES}

3.1 Percentage Gravel in Wind Erosion Test Trays. . . . . . . . . . . . . . 3.8

4.1 Tests and Initial and Post-Test Soil Moisture Content (percentage of dry soil mass) Results . . . . . . . . . . . . . . . . . . . . . . 4.10

4.2 Measured Surface Deflation Rates for 10 and $20 \mathrm{~m} / \mathrm{s}$ Wind Speeds and both Initial and Aged Conditions . . . . . . . . . . . . . . . . 4.18 



\subsection{INTRODUCTION}

Protective barners have been identified as integral components of plans to isolate defense waste on the Hanford Site (DOE 1987a). The use of natural materials to construct protective barniers over waste sites is being considered. Design requirements for protective barriers include preventing exposure of buried waste, whether by natural or man-caused disturbances, and restricting penetration or percolation of surface waters through the waste zone. A barnier design proposed for and climates such as Hanford (DOE 1987b) employs a series of layers, including gravel and riprap, sand, an impermeable layer, and soil and gravel mixtures.

Adams and Wing (1986) reported that various aspects of protective barrier performance have been evaluated with both mathematical models and field tests, and that these evaluations were continuing and additional investigations were planned. Resistance of the barrier surface to eolian forces was listed by the authors as one necessary area of study; both deflation due to wind erosion, and the opposite effect, deposition of sand, have the potential for reducing the effectiveness of the barrier to maintain adequate cover and prevent water infiltration at waste sites. In addition, the design of the composition and depth of the surface layer should also consider resistance to eolian forces. To address these concerns, Pacific Northwest Laboratory (PNL) (a) contracted with the U.S. Department of Energy (DOE) through Westinghouse Hanford Company (WHC) to study the effects of wind erosion on mixtures of soil and gravel.

PNL scientists used wind tunnel testing to investigate the erosive effects of wind forces on proposed surface layers for protective barniers. Mixed soil and gravel surfaces were prepared and tested for resistance to wind erosion at the PNL Aerosol Wind Tunnel Facility. These tests were the first of a series of planned tests to investigate surface deflation caused by suspension of soil from various surface layer configurations, and were used to test the suitability of the wind tunnel to make surface deflation measurements. Several of the current tests were replicates using similar surface configurations so that the test-to-test variations in measured quantities could

(a) Operated for the U.S. Department of Energy (DOE) by Battelle Memorial Institute under Contract DE-AC06-76RLO 1830. 
be established and used as a guideline for subsequent tests. Tests were selected based on information presented in an unpublished test plan by Carlson and consideration of the need to establish repeatability of wind tunnel test procedures.

Planning, testing, and analysis phases of this wind erosion project are coordinated with other tasks supporting the development of protective barniers. These tasks include climate-change predictions, field studies (admix test plots, natural analogs, and evapotranspiration), and modeling efforts (erosion, UNSAT, BIOPORT). Results of this project are important for the development of a suitable design for the barrier surface, but must be considered along with results of the other tasks. For example, because of possible effects of the wind-resistant surface layer on vegetation, plant growth and viability studies should be preformed. And, although certain fractional gravel covers prevent soil drying, and thus promote plant growth, excessive covers reduce plant community viability and restrict soil moisture evaporation. Windresistant surfaces must still be able to sustain plant growth and allow drying. Burrowing animals are also thought to present a major destructive force at the barrier surface, and the impact of plant community and surface layer composition on animal excavation must be considered.

This report provides results of preliminary measurements of deflation caused by wind forces over level surfaces. Section 2.0 reviews surface layer characteristics and studies on wind erosion, describes effects of the erosion, and discusses wind tunnel modeling. Materials and methods of the wind tunnel tests are discussed in Section 3.0. Results and discussion are presented in Section 4.0, and conclusions and recommendations in Section 5.0.

This report does not consider formation of large structures such as blowouts, other surface disturbances, or deflation caused by water erosion. Water erosion specific to the Hanford Site is being studied currently as another part of the barrier development project and may use a model based on climate, surface topography, vegetative cover, and soil characteristics such as that presented in Nylan and Lane (1986). Future planned work includes continuation of the present experiments and other deflation and deposition tasks. Tests of the wind tunnel to represent natural wind erosion conditions should continue, and the effects of test bed length, air turbulence, and terrain microrelief should be considered. 


\subsection{BACKGROUND}

Protective barrier performance standards are currently being developed for internal (water percolation rate downward toward the waste site) and external barrier performance (wind and water erosion, other physical deterioration, and presence of a viable plant community). This section discusses the composition of the surface layer, provides a review of wind erosion and the influence of wind erosion on the proposed barrier design, and debates the suitability of wind tunnel tests to provide useful wind erosion data for use in barrier modeling and design.

\subsection{SURFACE LAYER CHARACTERISTICS}

The design of a protective barrier for waste-site containment must include a surface that will be stable and continue to isolate the waste in the future. A detailed description of the current barrier design proposed for the Hanford Site is provided in Adams and Wing (1986), and a sketch of the layered design is shown in Figure 2.1.

Determination of suitable candidate surfaces requires consideration of many variables, including the potential degradation of the surface over the 10,000-year life span of the barrier, which would limit use of an impervious surface over waste sites. If a natural surface layer is used, it must provide a suitable environment to support a viable plant community and retain water from rainfall and snowmelt in the fine soil reservoir for subsequent release by evaporation and transpiration. Mixing gravel with soil has the potential for limiting deflation caused by wind erosion while still providing a surface with the desired capabilities. An alternative approach of placing a thick layer of gravel on the surface, while protecting the soil surface from wind erosion, would prevent plant growth and severely limit surface evaporation, thus enhancing water infiltration and drainage into the barrier's interior. However, a thick gravel cover, while temporarily contributing to decreased barrier performance, would probably not remain stable over a long period of time. It is likely that the combined effects of freeze-thaw, shrink-swell, root pressures, and animal burrowing would produce a mixed soil and gravel morphology, regardless of whether the gravel was initially a surface layer or an admix. 

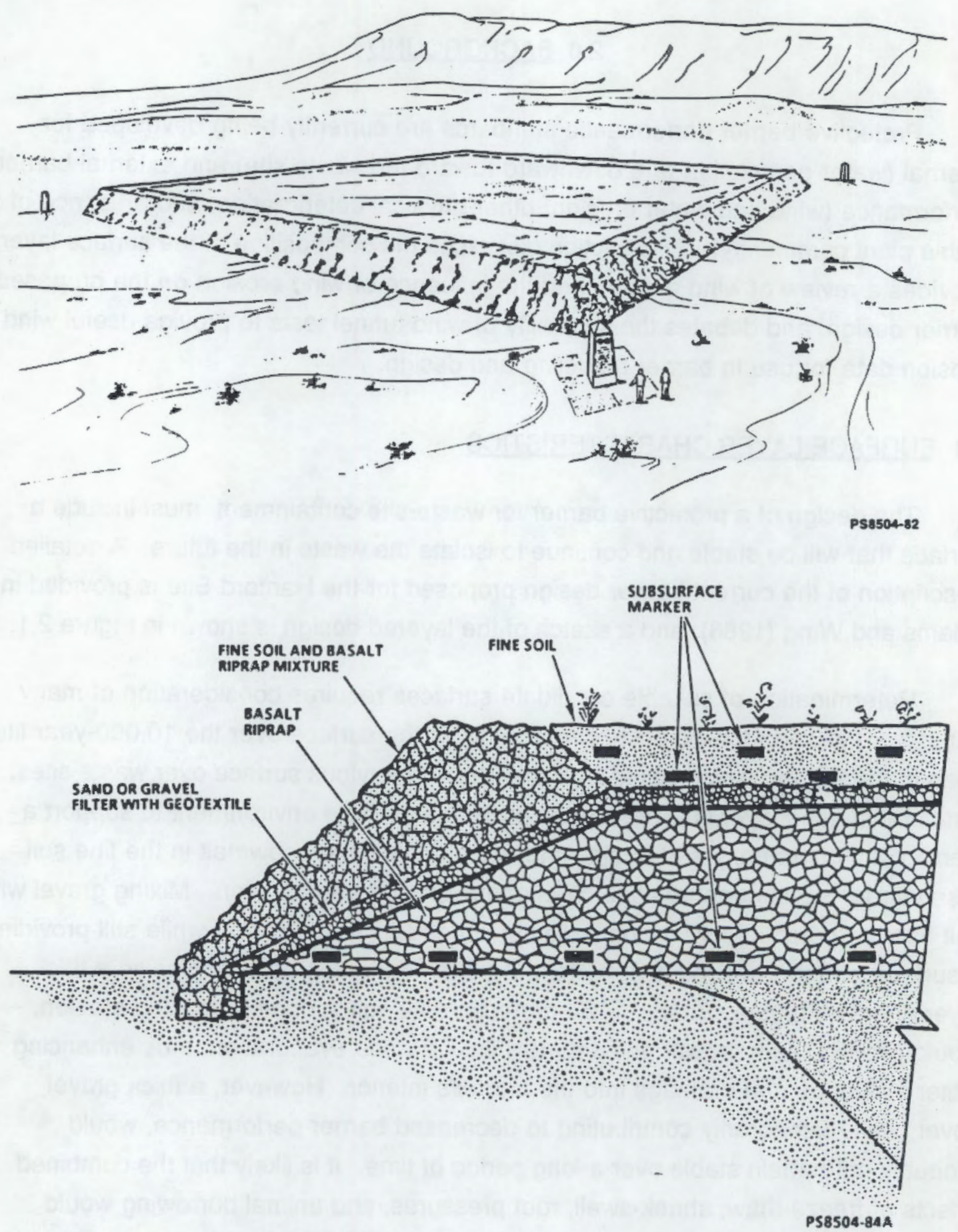

FIGURE 2.1. Conceptual Design of Multilayer Protective Barrier (After Adams and Wing 1986) 


\subsection{WIND EROSION}

The effects of wind erosion and deposition on natural and cultivated surfaces have been the subject of many decades of study. The potential cost of the loss of valuable topsoil has warranted sustained investigations primarily of the erosion, or deflation, of soil surfaces. The goals of these studies have been both to understand the processes of deflation and to devise methods of stabilizing surfaces from the effects of deflation. A partial listing of these studies includes Bagnold (1941); Chepil and Milne (1941); Chepil (1945a, 1945b, 1950); Zingg (1949); Chepil and Woodruff (1963); Chepil, Armbrust, and Siddoway (1964); and Logie (1981, 1982).

More recently, investigations of the rates of resuspension of materials deposited to various surfaces have been performed. Resuspension of radioactive materials deposited during fallout from atmospheric weapons tests, or from postulated power plant accidents, could provide health risks and has been studied extensively. Other materials such as mill tailings, waste sites, mineral (asbestos) fibers, and certain toxic or hazardous materials can also present resuspension concerns. Summaries of resuspension data may be found in Sehmel $(1980,1984)$. These studies provide a background for the current work involving the long-term stabilization of natural surfaces by describing mechanisms of wind erosion; however, wind erosion information specific to the protective barrier must be obtained before the completion of modeling efforts and before appropriate construction materials can be selected.

Wind erosion studies performed over past decades have revealed important air and surface characteristics that influence wind erosion. Important properties and characteristics of air include wind speed, turbulence, density, and viscosity. Important properties and characteristics of soil surfaces include soil moisture content; a covering layer of vegetation, gravel, or other material; topography; soil structure; and roughness. Aspects of soil structure influencing resistance to wind erosion include composition (clay, silt, sand, and organic matter); particle size distribution (including gravel mixtures); and the presence of nonerodible aggregates or clods.

Soil particles are transported by three wind erosion processes: 1) surface creep, 2) saltation, and 3) suspension. Surface creep involves the transport of relatively large particles (about $1 \mathrm{~mm}$ in diameter) by sliding or rolling in the direction of the wind vector. Under sufficiently high wind forces, gravel particles may be 
dislodged and slide or roll downwind. At lower wind speeds, gravel particles may influence the local distribution of wind forces by protruding into the air flow boundary layer to a greater extent than the surrounding surface and deflecting wind forces toward its base. These forces may dislodge smaller soil particles, which may eventually dislodge support for the gravel particle and cause it to rotate to a new position. Rotations perpendicular to the wind vector were observed in the current study; gravel oscillated from one side to the other as support was eroded. Logie (1982) observed movement of spheres and gravel into the direction of the wind vector when placed on a flat sand surface.

Saltation occurs when wind-induced low pressure forces above a particle are sufficient to overcome attractive forces between the particle and the surface and the gravitational force on the particle. Saltation acts primarily on particles about $100 \mu \mathrm{m}$ in size and is characterized by an initial vertical particle trajectory that is followed by transport back to the surface at a shallow angle of approximately $15^{\circ}$. The impact of saltating particles on surfaces may be a major driving force influencing wind erosion. The kinetic energy of a saltating particle is significant because of its large impact velocity and greater than average particle mass. On impact, such particles have been shown to enhance suspension of soil particles, and across long surfaces, a cumulative avalanching effect may occur. Under the influence of very high wind speeds, gravel may be transported in a manner similar to that of saltating soil particles. Although soil particles may attain an initial height of $1 \mathrm{~m}$, larger gravel particles may be expected to lift only a few centimeters off the surface.

Soil particle suspension, the third process of wind erosion, represents the majority of the loss of surface mass. Suspension occurs under the direct influence of wind forces as does saltation; however, suspension is also influenced by both surface creep and saltation. Suspension of particles often occurs in bursts following dislodgement of surface gravel, or following the impact of saltating particles. Particles transported by suspension are typically about $100 \mu \mathrm{m}$ or smaller.

\subsection{EFFECTS OF WIND EROSION ON BARRIER SURFACES}

The effects of eolian processes on protective barrier performance are grouped into two categories, deflation and deposition. Deflation effects include loss of surface soil, especially during extreme wind events, which results in a gradual lowering of the 
surface elevation. Such a decrease in the thickness of a barrier reduces its capability to prevent water percolation into the waste zone by limiting the volume of the fine soil reservoir (the surface layer) and possibly reducing the viability of the plant community. An additional potentially significant form of deflation involves the formation of surface depressions such as blowouts. These structures are formed because of high wind forces directed toward the ground in the wake of nearby large objects. They may form more spontaneously if stabilizing plants are dislodged. In addition to deflation caused by normal weathering processes, deflation may be enhanced by surface disturbances, whether man-caused or as a result of burrowing animals.

In the field, deposition effects include displacement of fine-grained surface soils with deposits of wind-borne sand particles and the formation of sand dunes. The potential for transport and deposition of sand exists on the Hanford Site, and two sets of sand dune fields and several probable blowouts have been identified in a draft report by Kasper and Glantz. Should fine-grained surface soil be displaced with deposits of coarse sand, the capacity of the barrier surface layer to act as a water reservoir could be reduced. In addition, the presence of a sand cover or sand dunes could displace desired species of plants, thus reducing levels of evapotranspiration.

Several characteristics of the proposed protective barrier surface layer and wind forces are considered important in defining the worst-case potential for wind erosion, or deflation, from barrier surfaces. Surface layer characteristics include 1) soil type and particle size; 2) gravel size, shape, and percentage of the surface layer; 3) soil moisture content and density; 4) presence or absence of an established plant canopy or a plant root structure (especially following a range fire); and 5) presence or absence of surface crusts, including desert pavement, lichen-cryptogamic, raindropimpact, and chemical crusts. Characteristics of the wind forces driving deflation and other conditions affecting wind erosion include 1) friction velocity, 2) wind speed, 3) yearly precipitation and temperature cycles, 4) terrain microrelief, 5) burrowing animal mounds, and (6) wind turbulence.

\subsection{WIND TUNNEL MODELING}

Comparison tests of deflation on different surfaces require that similar erosive forces be applied. These conditions are very difficult to achieve in the field where 
high wind speeds are infrequent, nonuniform in direction, and inconsistent. However, wind forces are controlled in a wind tunnel to allow replication of wind forces from test to test and provide a basis for comparing various surfaces.

The differences between laboratory and field conditions must be considered when absolute measurements of deflation are attempted in a wind tunnel. Surfaces or surface crusts may be manufactured in the laboratory or obtained in the field and transported to the laboratory. Boundary layer depth is much less in wind tunnel experiments than under actual field conditions. However, this does not affect measurements of deflation because the erosive forces at surfaces are related to surface shear forces, which are indicated by surface roughness and friction velocity, both of which can be determined from boundary layer profiles. Multiple-direction weathering of surfaces in the field, as influenced by prevailing winds, is different than the single-direction weathering in wind tunnels. Although not anticipated to be of importance to rate of deflation, the effect of multiple-direction weathering could be investigated in a wind tunnel by rotating the test surface within the test section.

Another difference between laboratory and field tests includes the unsteady nature of natural winds. Large-scale turbulent structures, such as gusts or eddies near objects, may be responsible for initiating deflationary processes such as creep, saltation, and particle suspension in the field. For example, a normally stable surface may deflate during exposure to a $15 \mathrm{~m} / \mathrm{s}$ ( $33 \mathrm{mph}$ ) mean wind speed because of the occurrence of wind gusts that bring large erosive forces to ground level. Wind tunnel experiments with steady, sustained wind speeds equivalent to the gusts (i.e., equal friction velocities) may be used to investigate the effect of the gusts, or the gusts may be reproduced mechanically in the wind tunnel.

An important difference between laboratory and field tests is the length of the surface over which erosive forces act. Saltation has often been determined to have an avalanching effect on wind erosion. Particles are suspended and then fall back to the surface where their impact causes other particles to suspend. Similar increases in deflation occur because of surface creep. Because of the limited length of the exposed surface in wind tunnels, any avalanching effect would be conservative, and measured rates of deflation would be less than those actually occurring in the field. Fortunately, several techniques exist for measuring the effect of avalanching particles. The length of the test bed may be altered; a measure of larger deflation rates over the 
longer surfaces would indicate the magnitude of the effect of avalanching particles. Another approach is to inject a characterized saltation force, perhaps using spherical glass beads, and compare the resulting soil particle suspension with and without induced saltation. This approach has been used previously by Fairchild and Tillery (1982) and Borrmann and Jaenicke (1987). In these studies, saltation was shown to increase soil particle suspension rates, but the effect on surface stabilization, or the ability of the surface to develop a protective crust was not investigated. The effect of saltation is anticipated to decrease as a surface crust is formed by weathering processes in the field. 



\subsection{MATERIALS AND METHODS}

Mixtures of McGee Ranch silt-loam soil, river gravel, and minute quantities of fluorescent tracer were prepared in flat trays and weathered in a wind tunnel at high wind speed to form surfaces representative of natural windblown desert areas. Gravel size and percentage of mixture were varied to determine the effect of gravel on wind erosion. Air flow boundary layers were developed upwind of the test trays, and measurements of suspended particle concentrations were made within the flow boundary layer. A mass balance analysis was performed by comparing the amount of soil particle mass coilected in air samples to the bulk mass lost from the test tray. Measurements were performed over about 24-hr periods to determine the potential for each surface to harden and develop a surface crust resistive to wind erosion when exposed to constant wind speeds.

\subsection{WIND TUNNEL FACILITY}

All wind erosion tests were conducted at the Aerosol Wind Tunnel Research Facility at PNL. This facility, shown in Figure 3.1, is located on the Hanford Site in southeastern Washington. It contains an environmental wind tunnel in which air flow profiles and boundary layers are closely controlled. The facility is described briefly below; additional information on the facility, wind tunnel, and aerosol science capabilities can be found in Ligotke et al. (1986).

Wind speed, relative humidity, temperature, and lighting are controlled within the wind tunnel. The $70 \mathrm{~m}^{3}$ wind tunnel is constructed of stainless steel for ease of cleanup, except for the transparent Lexan ${ }^{\circledR}$ walls and ceiling of the primary test section. Three test sections are used for a variety of environmental and engineering projects. The wind tunnel is operated either closed-loop (recirculating), or in singlepass mode for airborne particles by use of a removable bank of high-efficiency particulate air (HEPA) filters in the return loop. This allows for simplified airconditioning and yet retains the applicability of the wind tunnel for particle resuspension studies that require clean air at the inlet to the test section. Designed to contain hazardous and toxic materials, the wind tunnel may be operated under negative air pressure, and exhaust flows from the system are passed through scrubbers and sets of HEPA filters. 


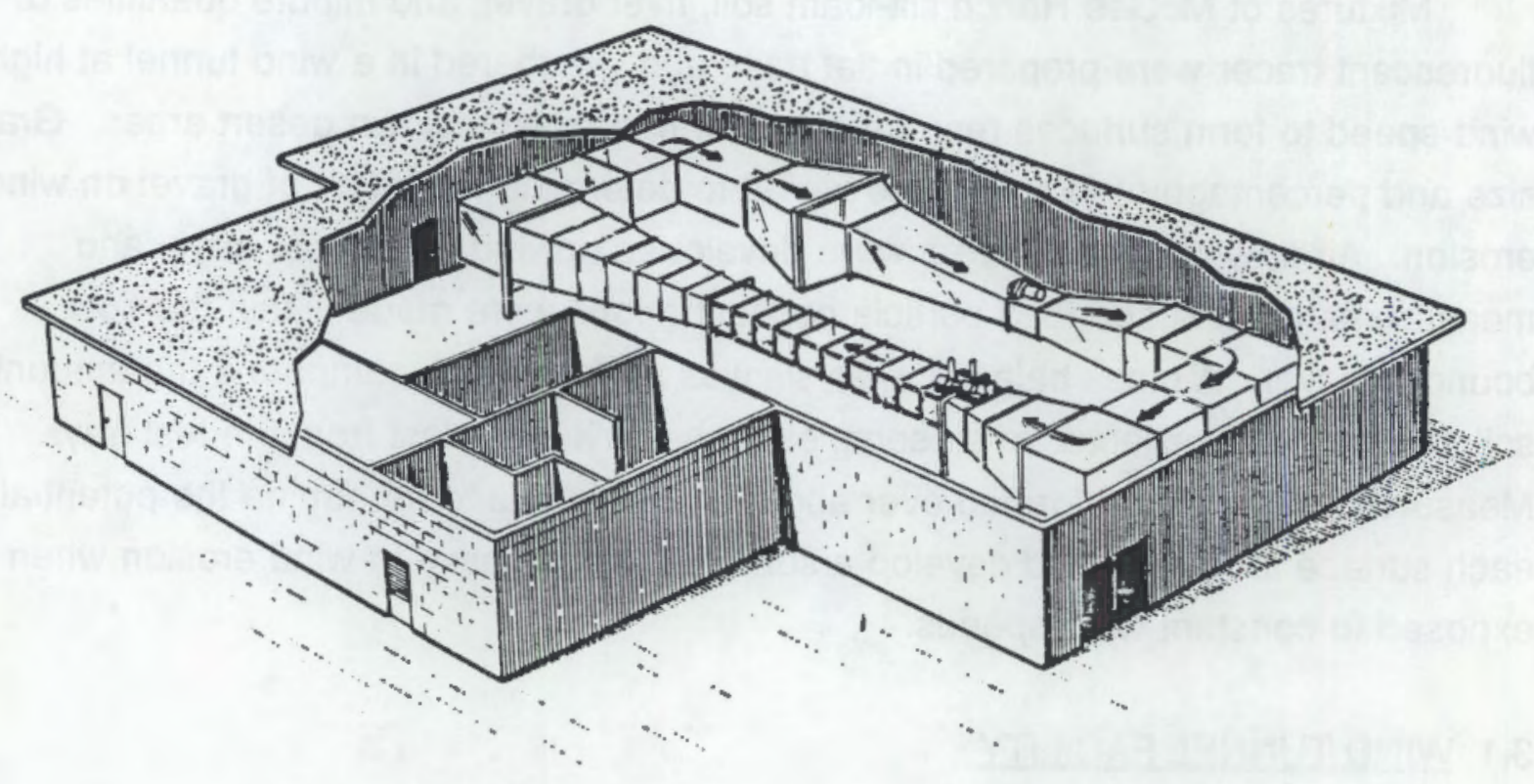

FIGURE 3.1. Orthographic Projection of the PNL Aerosol Wind Tunnel Research Facility

Air movement within the wind tunnel is maintained by a 1-m-dia variable speed fan operated by a 30-v dc motor. Wind speed profiles and boundary layers are uniform and controlled within the $0.61-\mathrm{m}$-square $\left(0.37 \mathrm{~m}^{2}\right)$ by $6.1-\mathrm{m}$-long test section used for all particle resuspension experiments. Maximum attainable velocity $30 \mathrm{~cm}$ above test surfaces is $31 \mathrm{~m} / \mathrm{s}$ (70 mph) for normal operating conditions; however, with modifications, velocities to $50 \mathrm{~m} / \mathrm{s}(120 \mathrm{mph})$ may be achieved. A reducing section at the inlet to the primary test section and turning vanes in all four bends limit upstream boundary layer depths and provide test section air flows having uniform horizontal and vertical velocity profiles. A $10-\mathrm{cm}$-deep false floor is provided below the aluminum plate floor of the test section. Trays used for resuspension experiments are placed on top of the aluminum floor or within the false floor, depending on tray height. Roughness elements or actual surfaces coated with a surface fixative are placed upwind of the test surface to provide a realistic boundary layer and to prevent scouring of the upwind edge of test surfaces. 
Environmental conditions are set and monitored as required by a computer control and data acquisition system. The system is also connected to aerosol generators and measuring devices to provide a systematic method for test operation and data acquisition. Temperature is measured by thermocouples, and humidity is measured optically using chilled mirrors. Lighting for the test section is provided by 400-W metal halide lamps, and additional ultraviolet (UV) lamps and UV-transparent plexiglass windows are used when necessary. Aerosol characterization instrumentation is available to measure concentration, particle size distribution, and composition of a wide range of airborne materials. Facility instrumentation also includes a remote laser single-particle analyzer for nonintrusive measurements of particle concentration, size, and velocity.

\subsection{SOIL AND GRAVEL CHARACTERISTICS}

Soils from two locations on the Hanford Site have been considered for use in constructing the surface layer of protective barrier structures; the primary location, the McGee Ranch, and a location termed Area 1 (Figure 3.2). In addition to resistance to wind erosion, important soil characteristics include water retention capacity and plantgrowth suitability. Only silt-loam soil from the McGee Ranch site was used in the present study. Two approximately $3 / 4$-full, 55-gal barrels of surface soil were used. Soil particle size distribution has not yet been analyzed, but will be completed during later stages of the current study. The McGee Ranch soils have been characterized by Last et al. (1987) and found to have 30 to $80 \%$ fines by weight passing a 230-mesh sieve $(62.5 \mu \mathrm{m})$. Soil from Area 1 was found by Myers (1985) to contain approximately $30 \%$ fines.

All gravels used were classified as river gravels rather than crushed gravels by observation of the presence of predominantly rounded edges. Two sources of river gravel were used in preparing test trays. A 3/8-in. washed, round pea gravel and a 3/4-in. gravel, were used (ACME Concrete Co., Richland, Wash.) as source gravels. The particle size distribution of the source gravels was determined as per ASTM (1984) Method D422-63. Narrow size distribution fractions were then separated from the source gravels by sieving and were used to prepare the test tray mixtures. Bulk gravel densities and packing densities were not determined. Gravel densities will be measured in subsequent experiments. 


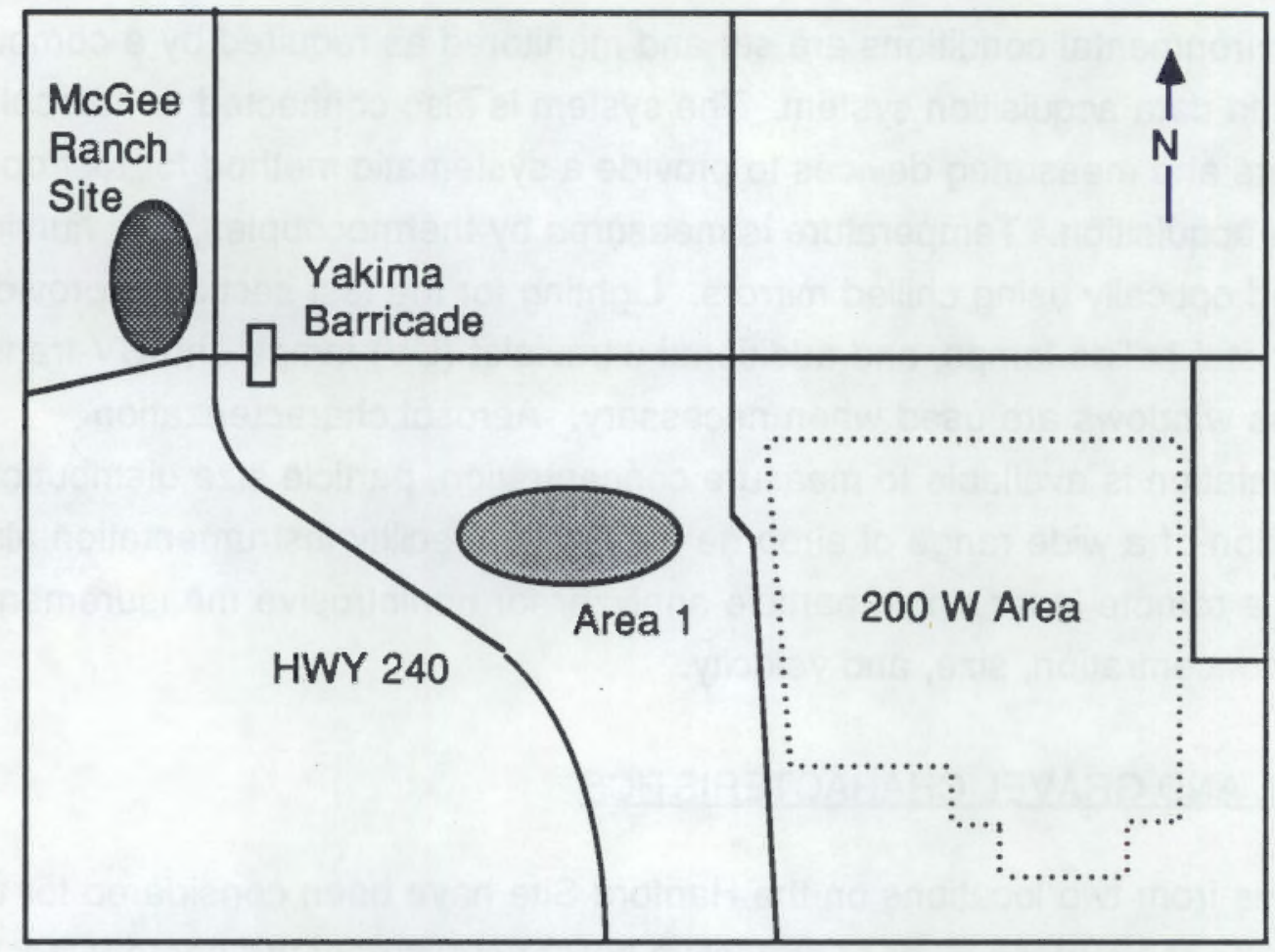

FIGURE 3.2. The McGee Ranch and Area 1 on the Hanford Site

A $0.7-\mathrm{cm}$ gravel was prepared by sieving the pea gravel. The particle size distribution of the entire pea gravel was determined by sieve analysis of two $3-\mathrm{kg}$ samples and is presented in Figure 3.3. All the gravel passed through a 3/8-in. sieve, and only 2 to $3 \%$ passed through a No. 10 sieve. The size distribution was seen to be approximately log-normal, and the mass median diameter, or characteristic dimension, of the gravel was $0.4 \mathrm{~cm}$. For preparation of the test mixtures, the pea gravel was sieved through a No. 4 sieve, and only that material retained on the sieve was used, resulting in particle diameters ranging from 0.48 to $0.95 \mathrm{~cm}$, or a characteristic gravel dimension of $0.7 \mathrm{~cm}$.

A 1.6- $\mathrm{cm}$ gravel was prepared by sieving the $3 / 4$-in. gravel. Results of a sieve analysis of an $80-\mathrm{kg}$ sample are shown in Figure 3.3. All the sample passed through a 1 -in. sieve, $29 \%$ was retained on a $3 / 4$-in. sieve, and $12 \%$ passed through a $3 / 8$-in. sieve. The characteristic dimension of the approximately log-normal distribution was $1.6 \mathrm{~cm}$. Because a narrow size distribution was required for wind erosion tests, only the fraction passing a $3 / 4$-in. sieve and retained by a $1 / 2-$ in. sieve was selected for 


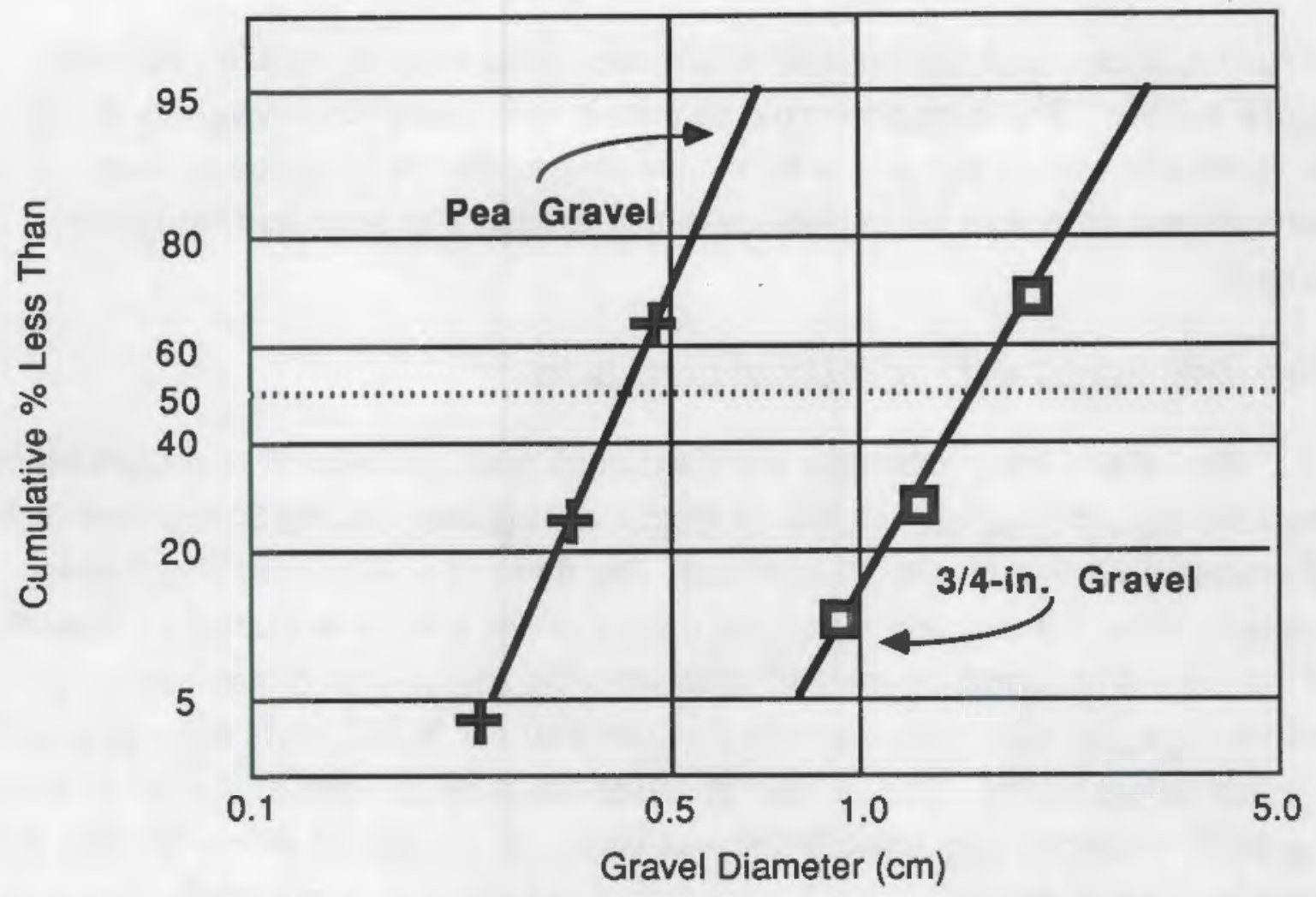

FIGURE 3.3. Particle Size Distributions of Pea and 3/4-in. Source Gravels for Wind Tunnel Surface Stability Tests

testing. This resulted in a gravel with particle diameters ranging from 1.3 to $1.9 \mathrm{~cm}$, or a characteristic dimension of $1.6 \mathrm{~cm}$.

\subsection{PREPARATION OF TEST SURFACES}

Soil, gravel, and tracer combinations were mixed and packed at specified density into shallow pans, or trays. Several additional trays were prepared for use in modifying the boundary layer of the air flow approaching the actual test surfaces. After preparation, trays were weathered by exposure to high wind speed. This was done to provide a surface representative of natural unvegetated windblown areas.

Surfaces were prepared by mixing soil and gravel. Various combinations were tested to investigate the influence of gravel size and percentage of mixture on surface resistance to wind erosion. Because of the mixing process, it was not practical to maintain natural surface crusts (lichen mats and crusts caused by rainfail). The effect 
of such surface crusts are anticipated to reduce initial rates of deflation from the barrier surface. These crusts should be tested, specifically for survivability during extreme wind events, but also to determine their stabilizing influence on fresh surfaces that otherwise fail to stabilize during exposure to sustained high wind speeds.

\subsubsection{Soil. Gravel, and Tracer Mixing Procedures}

Gravel and tracer materials were added by mass percentage to preconditioned soil batches. For example, to make a typical $100-\mathrm{kg}$ batch having $30 \%$ gravel, $30 \mathrm{~kg}$ of gravel would be added to $70 \mathrm{~kg}$ of soil. The mass of soil included all soil water present. Initial trial batches of soil and $0.7-\mathrm{cm}$ gravel were mixed using 21 repetitions of the cone-and-quartering method after removing agglomerated material using rollers. One part sodium fluorescein dye (uranine) per 10,000 parts soil was added as a tracer before mixing. This method provided adequate soil-gravel mixing; however, the tracer tended to agglomerate and was visible as occasional yellow spotting in the mixture. All subsequent mixtures were prepared using a concrete mixer. Soil was preconditioned using a No. 4 sieve to remove hard soil agglomerates and large organic matter such as roots. Approximately $1 \%$ of the soil was removed, dried in a desiccating oven, and then mixed with tracer powder. Soil and gravel were mixed for approximately $10 \mathrm{~min}$ in the mixer after the dried dye and soil mixture was added. No yellow tracer concentrations were observed using this procedure. Completed mixtures were immediately removed from the mixer and stored in plastic bags. Soil moisture content was analyzed pre-test and post-test.

\subsubsection{Iest Trays}

Test trays consisted of shallow rectangular sheet metal pans that were placed individually in the wind tunnel test section for wind erosion tests. The pans, shown in Figure 3.4, were $5.1-\mathrm{cm}$ tall, $50.8-\mathrm{cm}$ wide, and $45.7-\mathrm{cm}$ long. A $3.8-\mathrm{cm}$-tall support ring was used to allow soil and gravel mixtures to be packed to a depth greater than $5.1 \mathrm{~cm}$; the ring was only removed during wind tunnel tests. The surface area of the trays was $2310 \pm 25 \mathrm{~cm}^{2}$.

Soil mixtures were removed from storage, massed, and packed into the trays to achieve an initial density of $1.6 \mathrm{~g} / \mathrm{cm}^{3}$. The mixtures were compacted by repeatedly 


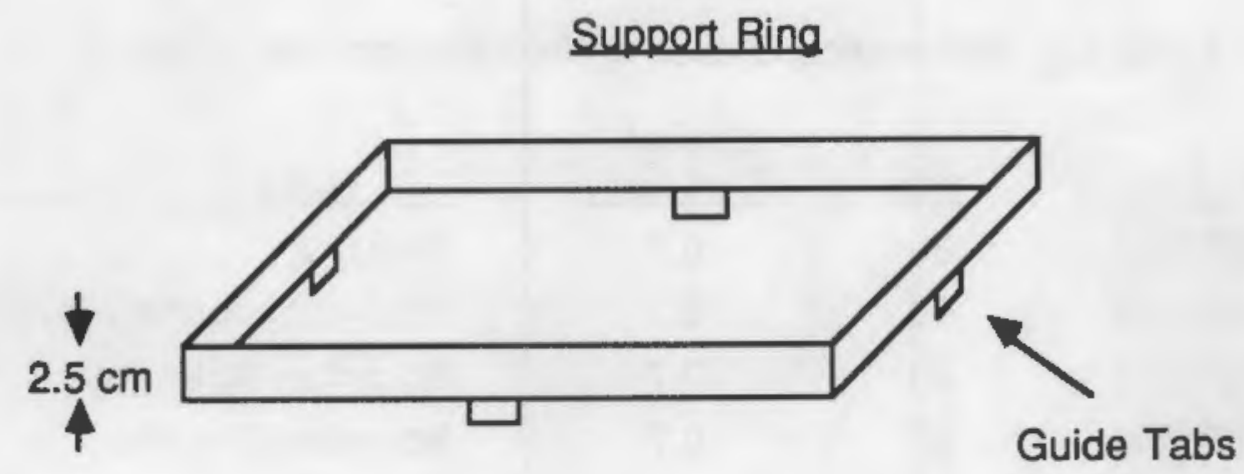

Wind Erosion Test Tray

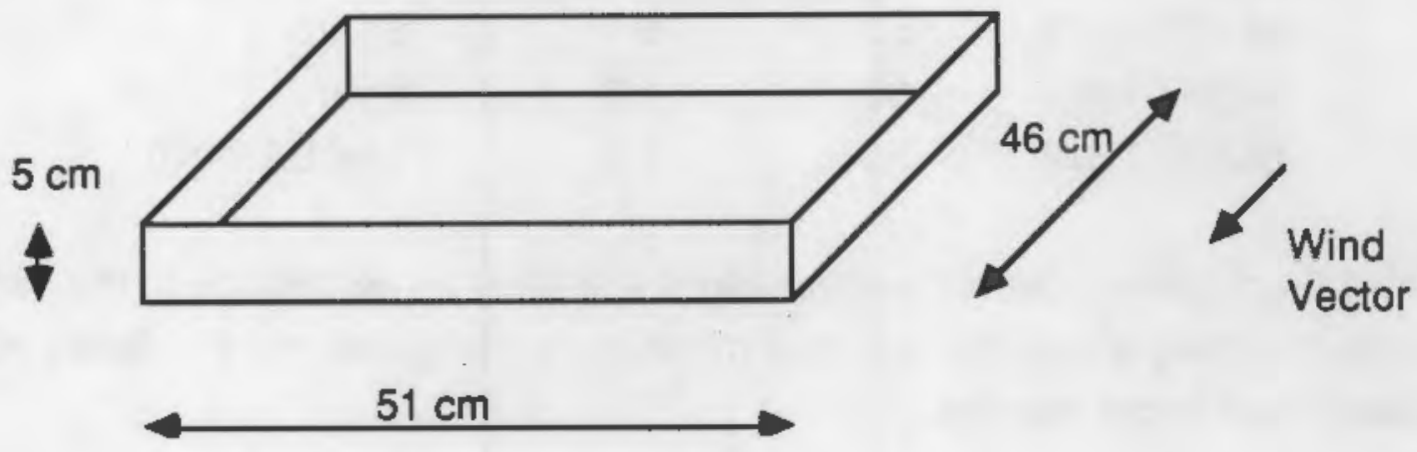

FlGURE 3.4. Schematic View of Test Trays and Support Ring

applying a compressive force of approximately $13 \mathrm{kN} / \mathrm{m}^{2}$. Using the support ring, mixtures of the $0.7-\mathrm{cm}$ gravel were packed 0.64 to $0.95 \mathrm{~cm}$ above the $5.1-\mathrm{cm}$-tall tray edge, and mixtures of the $1.6-\mathrm{cm}$ gravel were packed 0.95 to $1.3 \mathrm{~cm}$ above the tray edge. The extra packing height was required to allow pre-test conditioning (simulated weathering) of the surface and to eliminate any potential effects of exposed tray edges. The density of prepared trays was determined by comparing the mass and volume of the compressed mixture. Uncertainties in mass were insignificant, and potential errors in volume were limited to uncertainty in average height of the mixture, which was estimated by observation to be $\pm 0.3 \mathrm{~cm}$. The magnitude of the uncertainty in density should thus have been limited to $5.4 \%$, or approximately $0.09 \mathrm{~g} / \mathrm{cm}^{3}$.

Twelve test trays were prepared as shown in Table 3.1. Gravel concentrations were 30 and $50 \%$, by mass, for trays prepared with $0.7-\mathrm{cm}$ gravel and $30 \%$ for trays 
Table 3.1. Percentage Gravel in Wind Erosion Test Trays

\begin{tabular}{llcl} 
Tray No_- & (\%) & $\begin{array}{c}\text { Gravel } \\
\text { Size }(\mathrm{cm})\end{array}$ & \multicolumn{1}{c}{ Notes } \\
\cline { 2 - 2 } & 30 & 0.7 & Trial test \\
BAR87-TR2 & 30 & 0.7 & Trial test/boundary layer tray \\
BAR87-TR3 & 30 & 0.7 & Boundary layer tray \\
BAR87-TR4 & 30 & 0.7 & Boundary layer tray \\
BAR87-TR5 & 30 & 0.7 & Test BAR-005 \\
BAR87-TR6 & 30 & 0.7 & Test BAR-009 \\
BAR87-TR7 & 30 & 0.7 & Test BAR-011 \\
BAR87-TR8 & 50 & 0.7 & Test BAR-012 \\
BAR87-TR9 & 50 & 0.7 & Test BAR-013 \\
BAR87-TR10 & 50 & 0.7 & Spare \\
BAR87-TR11 & 30 & 1.6 & Spare \\
BAR87-TR12 & 30 & 1.6 & Test BAR-010
\end{tabular}

with 1.6- $\mathrm{cm}$ gravel. Gravel concentrations are listed as percentage of the mixture by mass, including gravel, soil, and soil moisture. All prepared trays included minute quantities of tracer material.

Trays were stored after preparation, overnight during tests and post-test, to limit loss of soil moisture content (SMC). Measurements indicated no significant loss of water occurred during storage periods. The tray ring was inserted, and a plastic sheet was taped securely over the top of the ring, approximately $3 \mathrm{~cm}$ above the surface. The seam between the ring and the tray also was taped. Measurements of tray mass indicated a consistent loss of mass, which totaled $15 \mathrm{~g}$, or $0.1 \%$ of the mixture's mass after 21 days. Assuming a SMC of $4.0 \%$, and that all the measured mass loss was due to water loss, such a mass loss would correspond to $2 \%$ of the SMC, or a decrease from 4.0 to $3.9 \%$.

\subsubsection{Surface Weathering}

Freshly prepared test trays did not resemble exposed natural surfaces until they were conditioned by exposure to high wind speeds in the wind tunnel to simulate natural weathering processes. Only a small amount of gravel was visible initially at 
the top of the level soil surface. After completion of the weathering procedure, gravel particles had been exposed and the soil surface was observed to be shaped by the influence of wind forces and the presence of exposed gravel particles. The rate of soil particle suspension from the trays decreased dramatically and then approached a steady state during the weathering process, which continued until the original surface had been deflated by more than the characteristic dimension of the gravel particles. All test surfaces were prepared for wind erosion tests using this weathering process.

Trays were placed in the wind tunnel test section behind boundary layer surfaces and marked with the direction of the wind vector. The wind tunnel was operated at wind speeds of 5,10 , and $22 \mathrm{~m} / \mathrm{s}(11,22$, and $49 \mathrm{mph}$, respectively [mph $=2.23 \times \mathrm{m} / \mathrm{s}$ ) for a total of $25 \mathrm{~min}$ for trays with $0.7-\mathrm{cm}$ gravel and $65 \mathrm{~min}$ for trays containing $1.6-\mathrm{cm}$ gravel. Visual observations made during conditioning of the $0.7-\mathrm{cm}$ gravel trays revealed that a small amount of surface dust and small organic matter were suspended at the lower velocity; however, nearly all deflation occurred at the highest wind speed. At $10 \mathrm{~m} / \mathrm{s}$, gravel began to appear after approximately $5 \mathrm{~min}$ as the surface soil was eroded. Noticeable soil particle suspension occurred near the edges of gravel particles--in areas of probable maximum wind shear--and gravel particles shifted occasionally as supporting soil was displaced. At $22 \mathrm{~m} / \mathrm{s}$, gravel movement became obvious for all exposed gravel particles, and some gravel saltation was evident. Soil particle suspension and gravel saltation occurred in bursts, as anticipated; one event would destabilize a region and result in a short burst of suspended material. Effects of gravel creep and saltation were similar. As gravel particles bounced along the surface, they dislodged other particles, causing a temporary, avalanching increase in saltation activity.

The simulated weathering process for the trays containing $30 \%$ of the $1.6-\mathrm{cm}$ gravel was similar to that of the $0.7-\mathrm{cm}$ gravels, with the exception of two noticeable differences: 1) initial erosion at $22 \mathrm{~m} / \mathrm{s}$ was slower than that observed for the $0.7-\mathrm{cm}$ gravel trays, and 2) pronounced surface channeling occurred. The initially slower rate of particle suspension was attributed to the larger size of the gravel for several reasons: 1) the lower surfaces of the large gravel particles were not exposed until a greater depth of soil had been removed, possibly reducing wind shear forces; 2 ) the larger gravel particles did not vibrate or shift position as rapidly as the smaller gravel particles, even when mostly exposed above the surface; and 3) saltation of gravel particles was extremely rare, resulting in a reduced influence on soil particle 
suspension. Although initially reduced, the rate of erosion from surfaces protected by large-particle gravel was anticipated to increase as the surface developed, primarily because the greater height of the gravel would disturb the flow boundary layer at higher elevations, thus deflecting greater shearing forces to the air/soil interface. Surface channeling was also thought to have been caused by the large particle size. Natural, uneven distribution of gravel protruding into the boundary layer would likely cause localized highly scouring shear forces, and the resulting areas of increased particle suspension would tend to propagate downwind. Channels were characterized by a direction roughly parallel to the wind vector and maximum depths of 2 to $3 \mathrm{~cm}$.

\subsubsection{Boundary Layer Surface}

Care was taken to present test surfaces with appropriate wind shear forces. Soil mixtures were packed and weathered, as explained above, to maintain the surface level above the lip of the test tray, and the flow boundary layer approaching test surfaces was modified by passing it over a surrogate surface. It was thought that wind eddies would develop downwind of exposed tray edges and would artificially increase wind erosion at the leading edge of the tray--possibly increasing erosion over the length of the test tray because of avalanching soil and gravel particles. This condition was avoided.

A second potentially serious problem was the probable scouring of leading surface edges by high wind speeds not representative of actual field conditions. Because of friction, a boundary layer develops as air flows around or over an object or surface. This results in a lower velocity near the surface and gradually increasing velocities at increasing elevations above the surface until, at some elevation, the velocity approaches the free stream or actual velocity. The shape of the boundary layer, or the velocity of the air very close to a surface relative to the free stream velocity, is determined by a number of conditions included in which is the form of the surface. The flat aluminum plate surface of the wind tunnel test section floor provides very little resistance (friction) to air flow, and velocities close to the surface are relatively fast. The rough surface of soil mixtures provided a greater degree of resistance to flow, and thus the relative velocity of air close to the test surfaces was slow. A section of boundary layer trays was provided immediately upwind of the test surface to develop an air flow boundary layer. 
Boundary layer trays consisted of soil mixtures having $30 \%$ by mass of $0.7-\mathrm{cm}$ gravel, which were weathered as described above for actual test trays. These boundary layer trays were used for all tests, including the test of a $1.6-\mathrm{cm}$ gravel. A special boundary layer tray for the $1.6-\mathrm{cm}$ gravel case was not required after boundary layer measurements indicated only a minor difference between the 0.7 - and 1.6-cm cases (see Section 4.2). Following the aging process, the surfaces of the boundary layer trays were fixed by spraying them with several layers of a watersoluble plastic coating. This allowed use of the boundary layer trays to condition the air flow boundary layer, but prevented erosion of the boundary layer trays from influencing particle suspension measurements. Two trays were placed in series upwind of the location occupied by the individual test trays during wind erosion tests. Measurements of boundary layers at the downwind edge of the paired boundary layer trays (see Section 4.2) were different from those above the aluminum plate floor, but similar to those measured above the downwind edge of two of the test trays. These results indicated that the boundary layer trays were required and that the method used was sufficient.

\subsection{TEST PROCEDURES}

Wind erosion tests were performed on six different trays. Each tray was positioned and supported in the test section in the same manner. Figure 3.5 shows a cross-sectional view the wind tunnel test section during wind erosion tests, including boundary layer and test surfaces. An attempt was made to measure threshold velocities of resuspension. Test sequences and procedures were performed similarly, although some improvements were incorporated after completion of the first test (BAR87-005).

\subsubsection{Cenfiguration of Test Surface}

Trays were placed individually into the wind tunnel test section immediately behind fixed (nonerodible) boundary layer surfaces. The test section was $10-\mathrm{cm}$ greater in width than the trays, and trays were centered with smooth aluminum surfaces installed at both sides at the level of the top of the trays. Trays were constructed smaller than the width of the test section to eliminate exposure of the test surfaces to the nonuniform wind speeds existing at the outer $7-\mathrm{cm}$ of the wind tunnel 


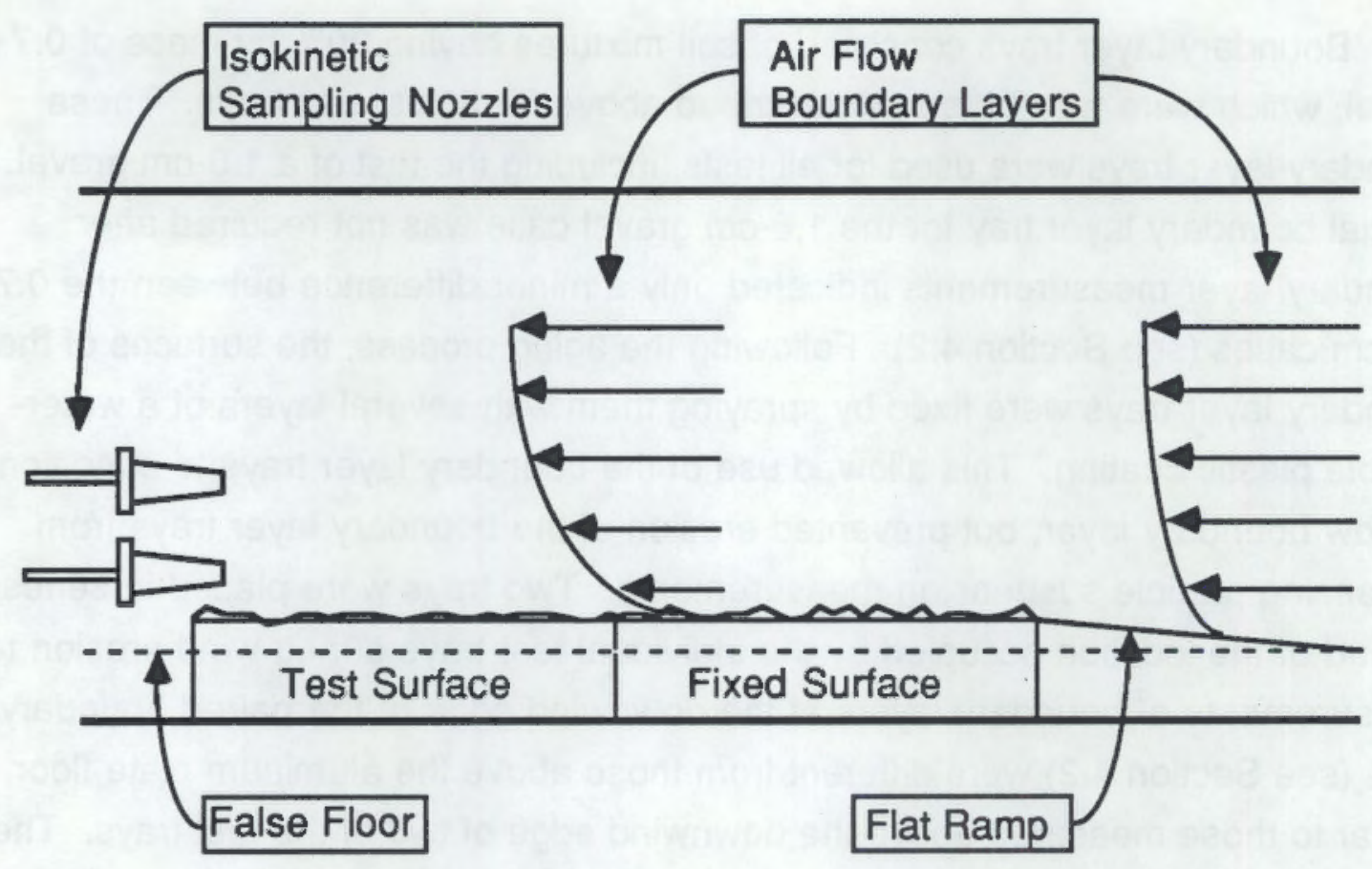

FIGURE 3.5. Cross-Sectional View of Wind Tunnel Test Section Showing Test and Boundary Layer (Fixed) Surfaces, Air Flow Direction and Boundary Layers, and Aerosol Sampling Probes

test section. This condition was caused by boundary layers next to the Lexan ${ }^{\circledR}$ walls of the test section. Wind speed was uniform across the width of the trays.

\subsubsection{Description of Test Sequence}

The typical duration of each test was 3 days, including approximately $24 \mathrm{hr}$ of measurements, with at least one 8- to 12-hr measurement occurning ovemight. During intervals when tests were temporarily halted, the test surfaces were covered with plastic seals to limit water loss to insignificant levels $(<<0.1 \% /$ day, see Section 3.3.2). Measurements, primarily by isokinetic sampler and mass balance, were performed at 5,10 , and $20 \mathrm{~m} / \mathrm{s}$. Measurements were performed sequentially for up to $26 \mathrm{hr}$ at each wind speed to provide information on surface stabilization and its influence on particle resuspension. Other measurements included test conditions (mean wind speed, temperature, humidity, and air pressure) and output of the remote aerosol particle analyzer. Surface $(0$ to $1 \mathrm{~cm})$ and the bulk $(0$ to $5 \mathrm{~cm}$ ) soil mixtures were sampled post-test and analyzed for SMC. 


\subsection{MEASUREMENTS}

Mean air flow and particle suspension characteristics were measured during each test. Flow boundary layers were measured to provide information on surface roughness and friction velocity. Soil moisture content of each test tray was measured post-test.

\subsubsection{Mean Air Velocity}

The mean wind speed was defined as the average velocity of air in the undisturbed region above the test surface boundary layer. A pitot-static tube was oriented within $5^{\circ}$ into the direction of air flow and at a location $30 \mathrm{~cm}$ above the test surface. Measurement of mean wind speed was made at the beginning and end of individual soil particle resuspension measurements. One-half of the dynamic vs. static pressure difference at the pitot-static probe was measured using a Dwyer Model 1430 micromanometer with 0.0001 in $-\mathrm{H}_{2} \mathrm{O}$ readability. Atmospheric pressure for the 300 Area was obtained from the Hanford Meteorological Station, and temperature within the wind tunnel was obtained using a General Eastern Model 1500 hygrocomputer. In addition to the pitot-static probe measurements, a hot film sensor connected to a TSI Model 1054A anemometer was used to monitor wind speed at centerline in the approach to the wind tunnel test section.

The horizontal wind speed profile over the test surface was measured from one side of the wind tunnel test section to the other and above the boundary layer. Boundary layer trays and a test tray were present during the measurements. A pitotstatic probe was placed in traverse at several locations, and mean velocity measurements were obtained.

\subsubsection{Air Flow Boundary Layer}

The vertical boundary layer was measured before and after selected tests. Boundary layers were measured over the flat plate aluminum surface of the wind tunnel test section, the trailing edge of boundary layer trays, and the trailing edge of actual test trays after selected tests. Boundary layer measurements were obtained by use of a pitot-static tube on a vertical traverse. 


\subsubsection{Threshold Velocity and Laser Particle Analyzer}

Wind speed was gradually increased at the beginning of each test in an attempt to measure threshold velocity. Use of a remote single-particle analyzer to augment threshold velocity measurements was only partially successful because of an inability to focus the sensitive volume of the device within the lower boundary layer immediately over test surfaces. The analyzer was instead focused $30 \mathrm{~cm}$ downwind and $10 \mathrm{~cm}$ above the surface (downwind of the isokinetic aerosol sampling probe and support). Particles diffused in the turbulence behind the isokinetic sampler were detected by the particle analyzer. Other threshold velocity measurements included observation and isokinetic aerosol samples at 5 and $10 \mathrm{~m} / \mathrm{s}$.

\subsubsection{Isokinetic Aerosol Measurement}

Samples of boundary layer aerosols were obtained as one of two primary resuspension measurements using sharp-edged isokinetic nozzle samplers (the other primary measurement was bulk tray mass, described below). Measurement of soil particle resuspension by isokinetic aerosol sampling probes was preferred to measurement of bulk tray mass; however, because only a fraction of the total boundary layer and tray width could be sampled using aerosol probes, results were compared with bulk tray mass measurements. This comparison provided a measure of potentially nonuniform soil particle suspension across the width of the test surface.

Suspended soil particles were collected on 47-mm glass fiber filters (Gelman Type A/E) and analyzed by gravitational and fluoroscopic methods. All sampling nozzles were sharp-edged and had $1.27-\mathrm{cm}$ diameters and $10.0-\mathrm{cm}$ lengths.

A manifold was used to operate a series of nozzles during each measurement. The manifold was connected to a vertical support, and nozzles were positioned horizontally at one adjustable measured distance above the average test surface during each measurement. One, two, or three samplers were operated within the surface boundary layer during tests; three samplers were typically operated during tests at $10 \mathrm{~m} / \mathrm{s}$ and two during tests at $20 \mathrm{~m} / \mathrm{s}$. Available high-volume air sampling capabilities limited the number of isokinetic samplers used during the high-velocity tests. One nozzle was periodically operated at an elevation greater than the height of the boundary layer to provide information on background aerosol concentration. 
Samples were obtained isokinetically; the velocity of the sample in the nozzle was equal to that in the surrounding air flow. The sharp edges of the sampling nozzles provided little resistance to flow, and nozzle geometry was chosen to limit turbulence both within the nozzle and upwind of its inlet. Because most samples were obtained within the boundary layer, the sample flow rate was reduced to less than that required for sampling in the free stream flow. For example, when sampling at an elevation $1.9 \mathrm{~cm}$ above the average surface, the sample flow rate was controlled at a rate 0.74 times that which would have been used had the nozzle been located above the boundary layer. Samples were primarily obtained at an elevation corresponding to a velocity of 0.74 times the free stream velocity; however, samples were also obtained at elevations corresponding to velocities of $0.55,0.87$, and 0.97 times the free stream velocity to provide information on vertical particle concentration profiles. Normalized boundary layer profiles were similar for all tests and provided information for suitable probe elevations.

Because of the inertia of sampled soil particles and the nonlaminar state of the boundary layer, particles drawn into the sampling nozzles did not always penetrate to the collection filter. This was taken into account in all data analysis procedures by employing the results of a series of calibration tests at 5,10 , and $20 \mathrm{~m} / \mathrm{s}$. Deposition of particles in the nozzle upwind of the filter was found to be a strong function of wind velocity. The total amount of deposited mass collected in the walls of a nozzle during selected tests was determined by rinsing the material from the nozzle with a known volume of distilled water and analyzing the resultant solution fluoroscopically. Probe loss was then calculated as the amount of soil deposited to probe walls divided by the sum of the same mass and the particulate mass collected on the filter.

Sample flow rate in isokinetic samplers was measured by passing the sample flow through a flowmeter. A vacuum gauge was also mounted to the discharge of the flowmeter and used to correct flowmeter reading for the reduced derisity of the sample flow. Calibrations were performed for both devices, and an analysis of potential errors was completed.

\subsubsection{Sample Mass and Tracer Material}

Use of aerosol probes to measure soil particle resuspension was limited to cases when more than $0.05 \mathrm{mg}$ could be collected on the filter substrate. Lack of 
adequate sample mass was anticipated during tests at low wind speed or when a surface crust was present to reduce particle suspension rates. A fluorescent tracer material was mixed with the soil and gravel to provide an additional method of measurement. Originally, the goal of tracer use was to provide analytical capability for samples containing more than $0.005 \mathrm{mg}$ of soil particle mass, or an improvement of 10 times over gravimetric analysis.

Initial estimates indicated that a mixture of 1 part sodium fluorescein (uranine) per 10,000 parts soil would provide a measurable tracer over natural soil fluorescence at the appropriate levels when samples were extracted in water. The aqueous analysis was more sensitive than use of a methanol extraction procedure. Uranine tracer was added to all soil-gravel batches prepared for resuspension tests.

Use of the tracer proved valuable during aerosol probe calibration tests, but did not increase the sensitivity of the gravimetric analysis for reasons discussed below (see Section 4.3).

\subsubsection{Bulk Tray Mass}

The change in total mass of the tested soil and gravel mixtures was measured during selected tests. No potential bias from mass deposited on test surfaces during wind erosion tests existed because of the HEPA filter bank located in the return section of the wind tunnel, the clean condition of the wind tunnel between the HEPA filter bank and the test section, and because the boundary layer trays were sealed with a plastic coating and did not resuspend. Background aerosol concentrations measured periodically during selected tests verified this assertion.

Test trays were removed before and after resuspension tests and their masses measured using a Sartorius Model 3807MP8 high-capacity mass balance. The device provided an accuracy and repeatability of better than $\pm 1 \mathrm{~g}$, or approximately 1 part per about 23,000 parts for the test trays. Repeatability was demonstrated by a series of measurements on a single test tray, and accuracy was confirmed periodically by the Hanford Engineering Development Laboratory's (HEDL) Standards Laboratory. The mass balance was also used to monitor long-term tray mass loss from presumed evaporation of soil water. 
Trays were removed from the test section of the wind tunnel and placed on the mass balance for analysis. The aluminum angle side support between the tray and the test section wall was removed, the aerosol probe manifold rotated to one side, and any soil material deposited just downwind of the trailing tray edge was brushed away before removing a tray from the test section. The reverse procedure was performed to re-install trays.

\subsubsection{Soil Moisture Content}

Soil moisture content was measured at the time test trays were prepared and after each test series was completed. Procedures followed were similar to those described in ASTM (1980) Method D2216-80. Deviation from standard procedures included post-analysis separation of the gravel fraction from the samples. This allowed determination of not only the SMC of the soil and gravel mixture, but also the SMC of the soil only. Two types of post-test samples were analyzed, surface and bulk samples. Surface samples were obtained by sampling the top $1 \mathrm{~cm}$ of soil over an area of approximately $100 \mathrm{~cm}^{2}$. Uncertainty of sample depth was estimated to be $\pm 0.5 \mathrm{~cm}$. Bulk samples were obtained by coring the entire depth of the mixture, approximately $5 \mathrm{~cm}$, within a circular area of approximately $20 \mathrm{~cm}^{2}$. Two surface and two bulk SMC samples were obtained post-test from each tested tray.

\subsection{INSTRUMENT OPERATION}

Instruments calibrated in the laboratory included the wind tunnel fan controller, a hot film anemometer, a flowmeter, and a vacuum gauge. Instruments calibrated by the HEDL Standards Laboratory included both mass balances. Other devices were calibrated by the manufacturer and supplied with calibration certificates. 'These included the micromanometer's micrometer and temperature and humidity probes. No absolute calibration of the fluorometer was required as all fluorometric data were based on relative comparison of a number of measurements.

Results of mean wind speed calibrations performed in the laboratory are shown in Figure 3.6. The standard for all wind speed measurements and calibrations was a Dwyer Model 1430 micromanometer; the stated accuracy of the device is \pm 0.00013 in $-\mathrm{H}_{2} \mathrm{O}$ for $1 / 2(\Delta \mathrm{P})$, and it is readable to $0.0001 \mathrm{in}-\mathrm{H}_{2} \mathrm{O}$. Potential errors associated with measurement of mean wind speed, because of limitations of the micrometer, 
were thus seen to be $0.2 \%$ or less. Magnitudes of real velocity fluctuations measured in the free stream flow ranged from 0.2 to $0.6 \%$ of the mean velocity for velocities between 5 and $25 \mathrm{~m} / \mathrm{s}$.

Calibration results of the flowmeter and vacuum gauge used to measure aerosol probe sample flow rates are shown in Figures 3.7 and 3.8. The flowmeter was a Dywer No. RMC-106 and was calibrated by comparison with a Dresser No. $1.5 \mathrm{M} 125$ roots meter and a Singer DTM-115 dry test meter. Both standards were calibrated by the HEDL Standards Laboratory. The maximum deviation of data from the flowmeter calibration was $5.3 \%$ at a flow rate of $35 \mathrm{lpm}$ (liters per minute); the average deviation over a $30-$ to $400-1 \mathrm{pm}$ range was $2.0 \%$. Sample air flow in the discharge of the flowmeter was at less than atmospheric pressure. Because of this, the actual flow rate was a function of both the flowmeter reading and the discharge vacuum. A standard 0 to $30 \mathrm{in} . \mathrm{Hg}$ vacuum gauge was used and was calibrated by comparison with a mercury manometer. For flowmeter discharge vacuums ranging from 0 to $20 \mathrm{in}$. $\mathrm{Hg}$, potential errors associated with the accuracy and readability of the vacuum gage corresponded to flow rate errors ranging from 0.05 to $0.7 \%$ (with an average of $0.29 \%$ ). Errors rapidly increased as the flowmeter vacuum approached absolute (30 in. $-\mathrm{Hg}$ ); however, flowmeter settings were controlled, and no samples were obtained with the vacuum greater than $20 \mathrm{in.}-\mathrm{Hg}$. The sum of maximum possible flow rate errors was therefore $\pm 6.0 \%$, and average anticipated errors were $\pm 2.3 \%$. 

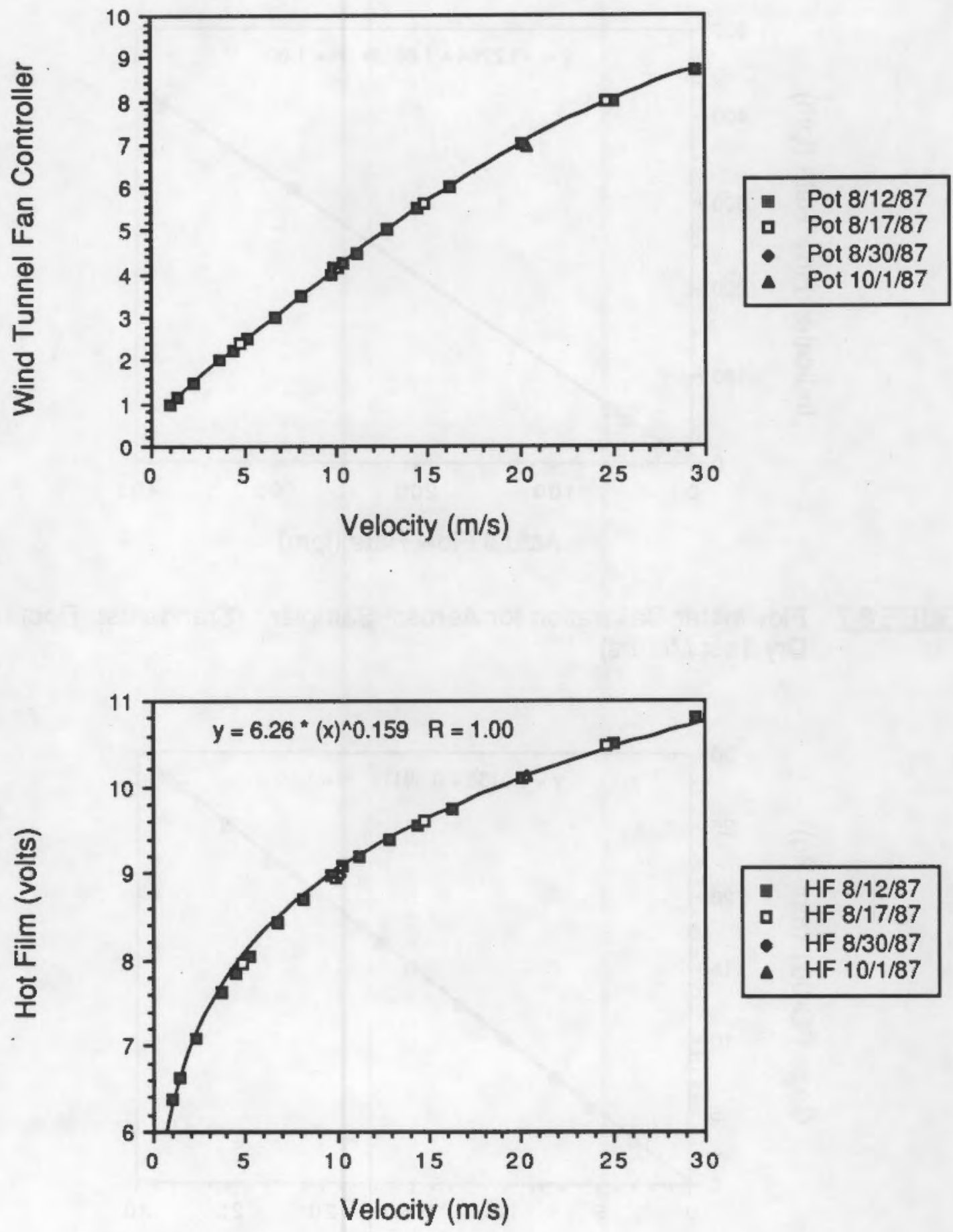

FIGURE 3.6. Wind Tunnel Mean Wind Speed Calibrations (Both the wind tunnel fan controller and a hot-film anemometer were calibrated. Standard: Pitot-static probe connected to a micromanometer. Data include periodic verification of calibration stability) 


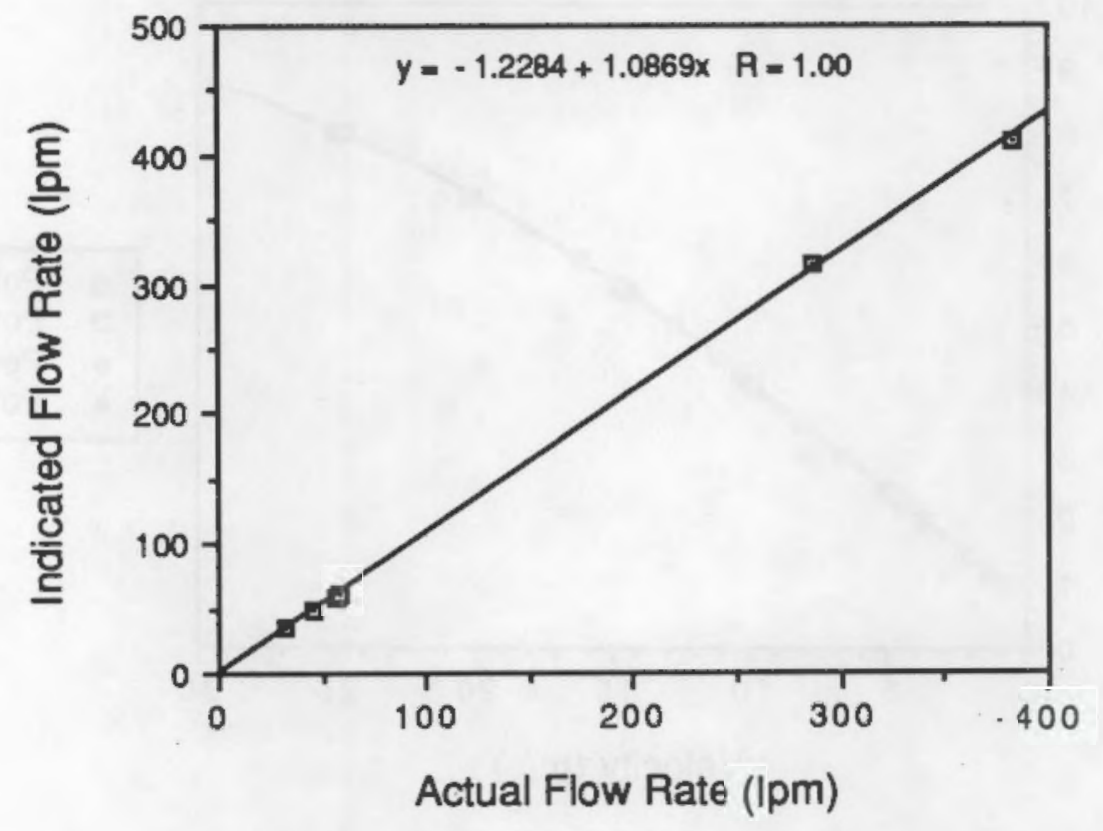

FIGURE 3.7. Flowmeter Calibration for Aerosol Sampler. (Standards: Roots and Dry Test Meters)

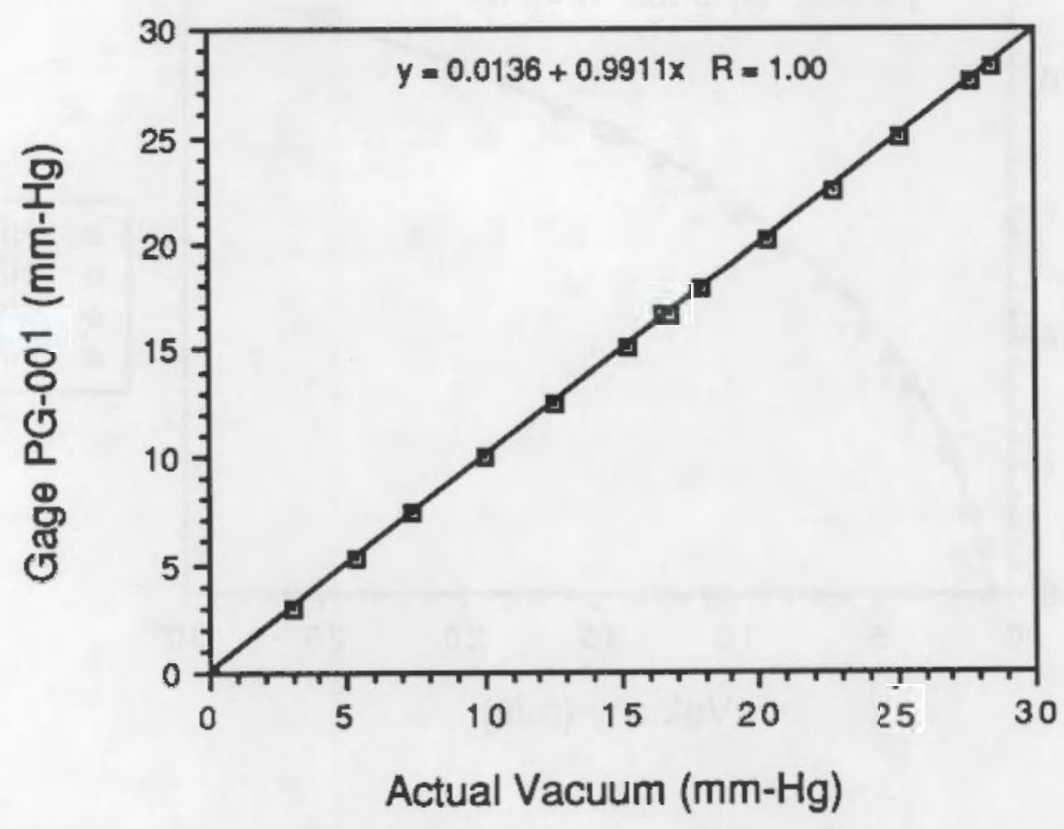

FIGURE 3.8. Pressure Gage Calibration for Aerosol Sampler. (Standard: U-tube mercury manometer) 


\subsection{RESULTS AND DISCUSSION}

Six tests of soil particle suspension, or surface stability, were planned and completed. Each test included approximately 22 individual wind erosion measurements. Important parameters included gravel size and percentage of the total mixture, wind speed, boundary layer, suspended particle concentration profile, and duration of exposure to steady mean wind speeds. Results of these experiments include discussion of flow boundary layers, surface roughness, friction velocity, test conditions, aerosol measurements, bulk tray mass change, and soil particie suspension versus wind speed and duration of exposure (aging).

\subsection{BOUNDARY LAYERS, SURFACE ROUGHNESS, AND FRICTION VELOCITY}

The horizontal velocity profile over the test surface, measured for a mean centerline velocity of $10 \mathrm{~m} / \mathrm{s}$, is shown in Figure 4.1. In the test section, test trays occupied the position between the 3-and 21-in. cross-sectional measurements. Between these positions, it was shown that the mean velocity was nearly constant, ranging from $0.99 \pm 0.01$ times the free stream velocity over the tray's (side) edges to $1.00 \pm 0.05$ times the free stream velocity over the tray's center. Mean air speed was shown to decrease rapidly between the tray's outer sides and the walls of the wind tunnel test section. This was due to the presence of a boundary layer extending outward from the walls of the test section. The reduced wind speed did not affect rates of soil particle erosion from test surfaces because of the centered position of the test trays. Eddies and other turbulent structures at the sides of the trays were minimized by use of flat aluminum spacers installed at and to the sides of the trays.

Boundary layers over the flat aluminum plate floor of the wind tunnel, the trailing edge of the boundary layer trays, and the trailing edge of two test trays are shown in Figures 4.2, 4.3, and 4.4. Boundary layers were measured for free stream velocities of $2.2,4.5,9.0$, and $18 \mathrm{~m} / \mathrm{s}$ over the aluminum plate floor, and at $5,10,15,20$, and $25 \mathrm{~m} / \mathrm{s}$ over the boundary layer trays. Post-test measurements over test trays were limited to $10 \mathrm{~m} / \mathrm{s}$. All boundary layers were normalized versus mean centerline velocity and plotted to provide comparison. Boundary layers existing over the boundary layer and test surfaces were thicker than those over the aluminum floor ( $90 \%$ of the free stream velocity is achieved $2.0 \mathrm{~cm}$ above the aluminum plate, but not 


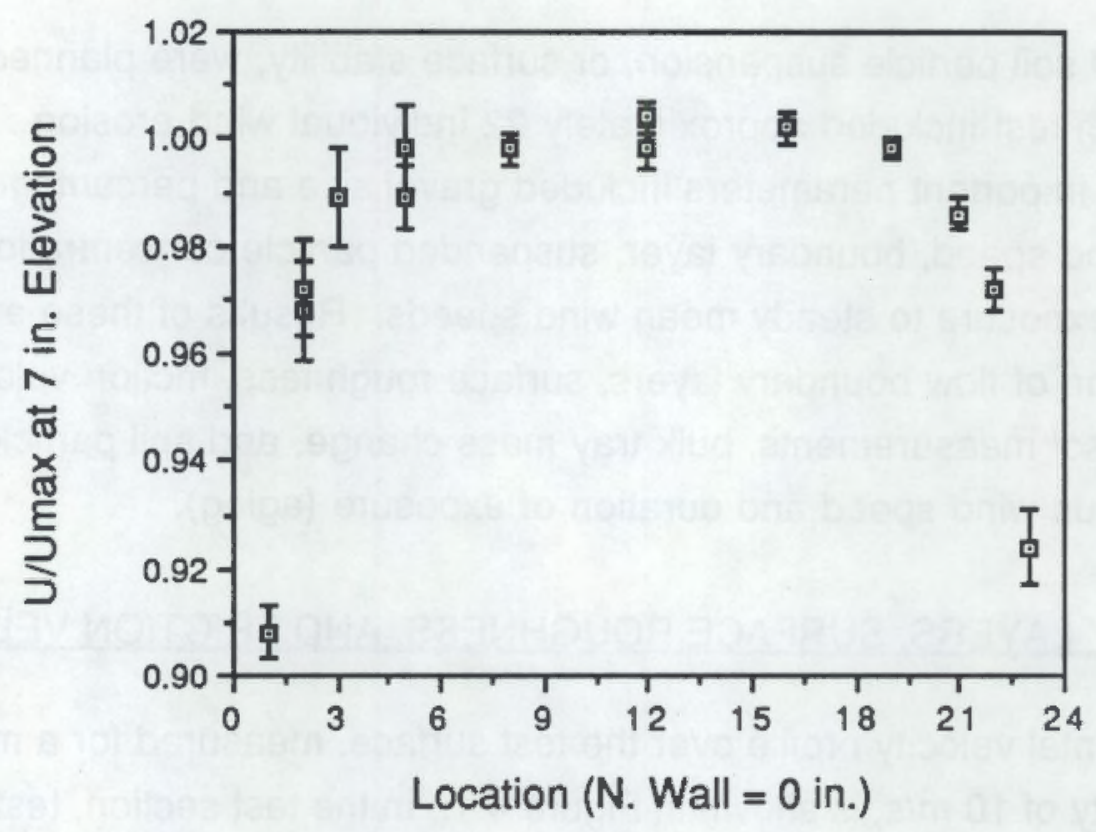

FIGURE 4.1. Horizontal Velocity Profile Across the Width of Test Surfaces. Test Surface Width Extended from the 3- to 21-in. Locations. Locations Measured from the North Wall of the Wind Tunnel Test Section.

until approximately $3.8 \mathrm{~cm}$ above the boundary layer and test surfaces). This was anticipated because of the greater roughness of these surfaces, and it indicates that use of boundary layer trays to modify the approaching air flow was required to prevent high-velocity scouring at the leading edge of test surfaces. Less difference between normalized low- and high-wind speed boundary layers was observed for the test surfaces than for the aluminum plate surface. This was primarily because of the lower velocities tested for the aluminum plate surface and the increased roughness of the test surfaces. No great difference between boundary layers over $0.7-\mathrm{cm}$ and $1.6-\mathrm{cm}$ gravels existed at a mean wind speed of $10 \mathrm{~m} / \mathrm{s}$.

Surface roughness and friction velocity parameters were determined for all three types of surfaces. These two parameters are useful because they relate surface characteristics and magnitude of the reference wind vector to average shear forces existing at the surface. These shear forces provide the impetus for initiating particle movement and suspension. Neither parameter is a directly measurable quantity. 

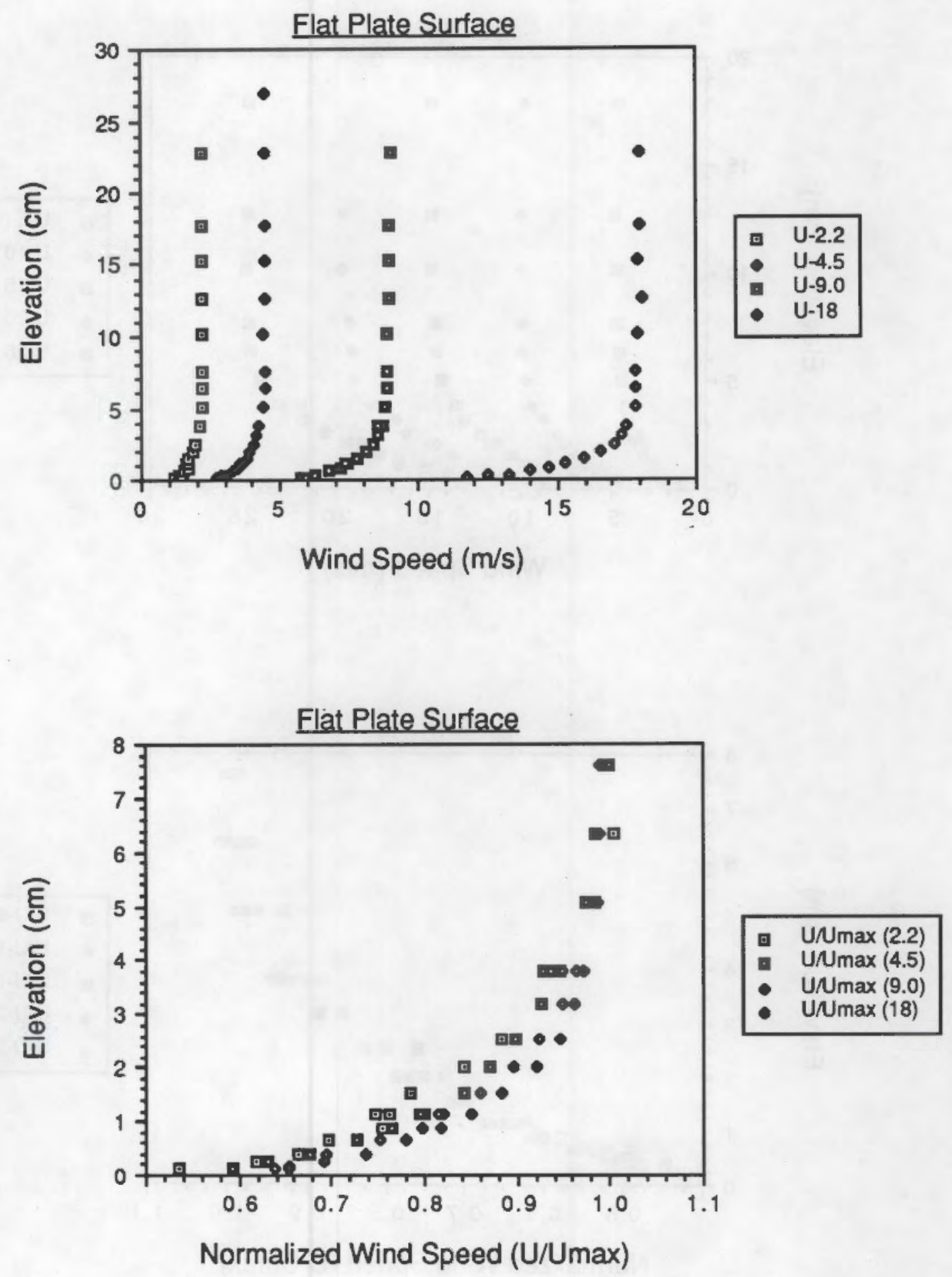

FIGURE 4.2. Standard and Normalized Boundary Layer Profiles over the Aluminum Plate Surface, Upwind of the Test Surface 

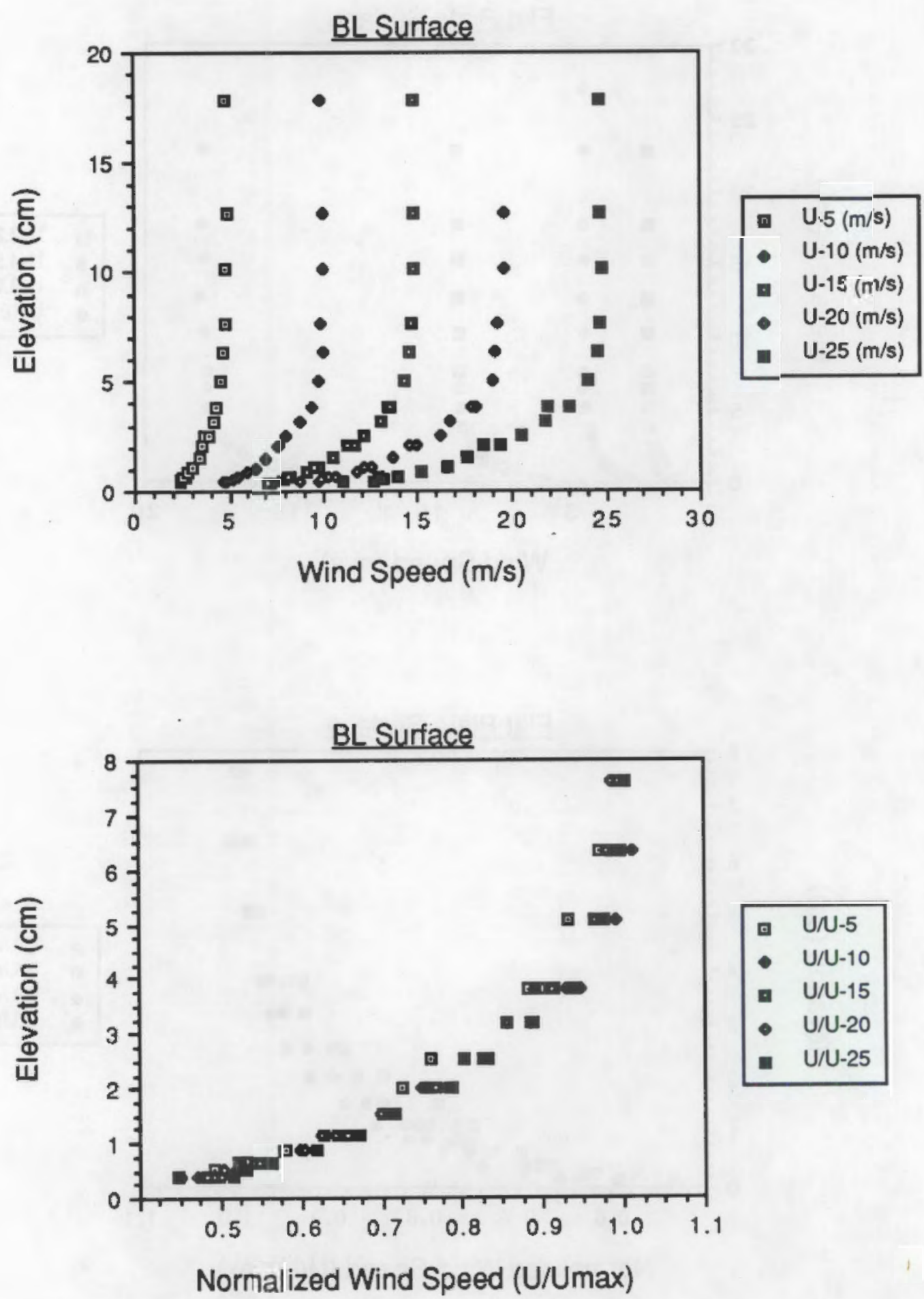

FIGURE 4.3. Standard and Normalized Boundary Layer Profiles over the Fixed Boundary Layer Surface, Upwind of the Test Surface 

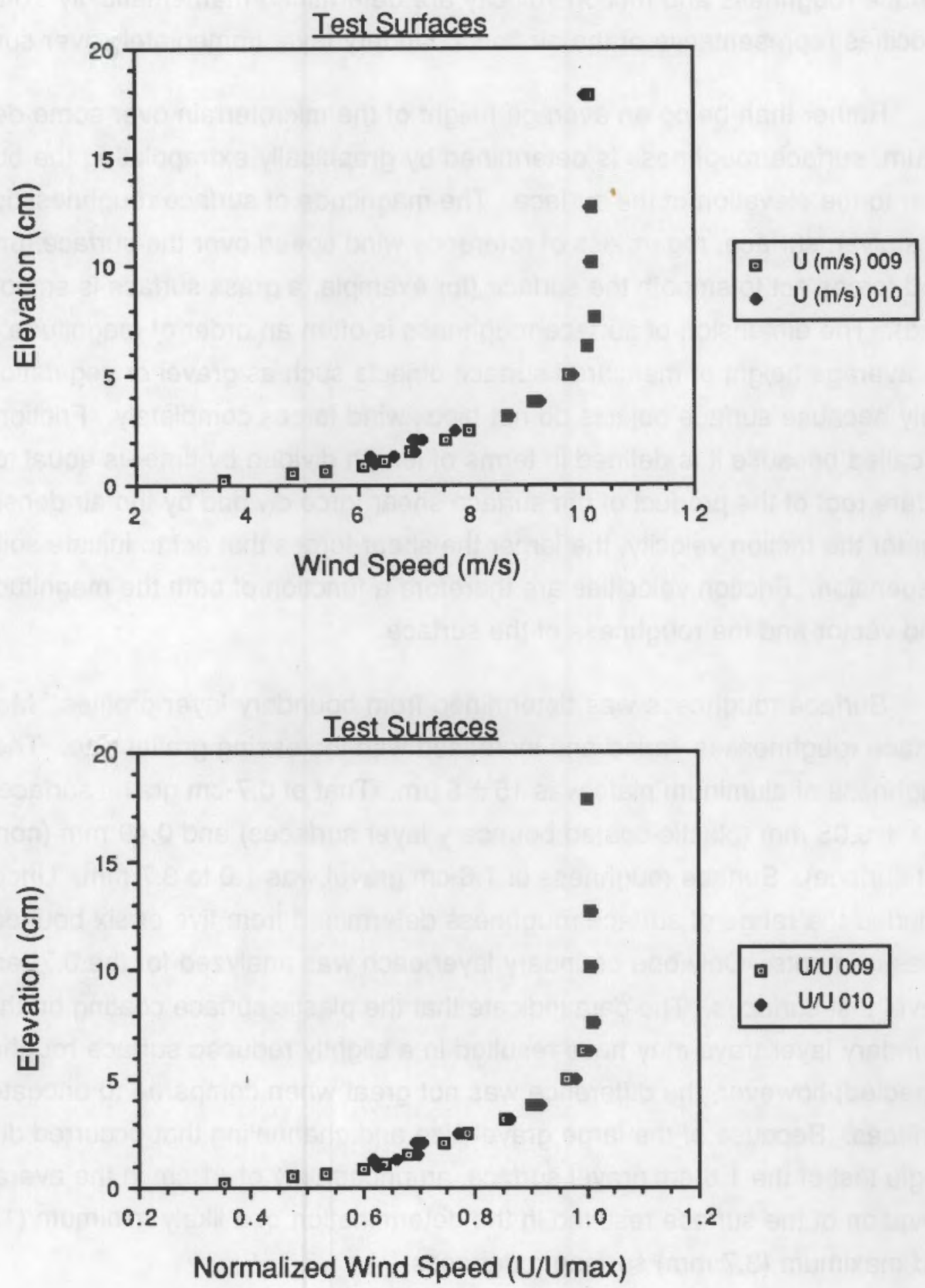

FIGURE 4.4. Standard and Normalized Boundary Layer Profiles Over the Test Surface. (Test 009 included $30 \% 0.7-\mathrm{cm}$ gravel; Test 010 included $30 \% 1.6-\mathrm{cm}$ gravel.) 
Surface roughness and friction velocity are determined mathematically from measured velocities representative of the air flow boundary layer immediately over surfaces.

Rather than being an average height of the microterrain over some defined datum, surface roughness is determined by graphically extrapolating the boundary layer to the elevation of the surface. The magnitude of surface roughness is constant for a given surface, regardless of reference wind speed over the surface, unless the wind forces act to smooth the surface (for example, a grass surface is smoothed by wind). The dimension of surface roughness is often an order of magnitude less than the average height of measured surface objects such as gravel or vegetation. This is likely because surface objects do not block wind forces completely. Friction velocity-so called because it is defined in terms of length divided by time--is equal to the square root of the product of the surface shear force divided by the air density. The greater the friction velocity, the larger the shear forces that act to initiate soil particle suspension. Friction velocities are therefore a function of both the magnitude of the wind vector and the roughness of the surface.

Surface roughness was determined from boundary layer profiles. Measured surface roughnesses varied and increased with increasing gravel size. The surface roughness of aluminum plate was $15 \pm 5 \mu \mathrm{m}$. That of $0.7-\mathrm{cm}$ gravel surfaces was $0.41 \pm 0.08 \mathrm{~mm}$ (plastic-coated boundary layer surfaces) and $0.49 \mathrm{~mm}$ (noncoated test surface). Surface roughness of $1.6-\mathrm{cm}$ gravel was 1.0 to $3.7 \mathrm{~mm}$. Uncertainties included the range of surface roughness determined from five or six boundary layer measurements. Only one boundary layer each was analyzed for the $0.7-$ and $1.6-\mathrm{cm}$ gravel test surfaces. The data indicate that the plastic surface coating on the boundary layer trays may have resulted in a slightly reduced surface roughness, as expected; however, the difference was not great when compared to uncoated surfaces. Because of the large gravel size and channeling that occurred during the single test of the 1.6- $\mathrm{cm}$ gravel surface, an uncertainty of $\pm 1 \mathrm{~cm}$ in the average elevation of the surface resulted in the determination of a likely minimum $(1.0 \mathrm{~mm})$ and maximum $(3.7 \mathrm{~mm})$ surface roughness.

Results of friction velocity calculations are shown in Figures 4.5, 4.6, and 4.7. Friction velocities were seen to be related to surface type. For wind tunnel wind speeds of 5 to $25 \mathrm{~m} / \mathrm{s}$, the friction velocity over the aluminum plate floor increased from 0.20 to $1.0 \mathrm{~m} / \mathrm{s}$, while the friction velocity over the $0.7-\mathrm{cm}$ gravel surface 

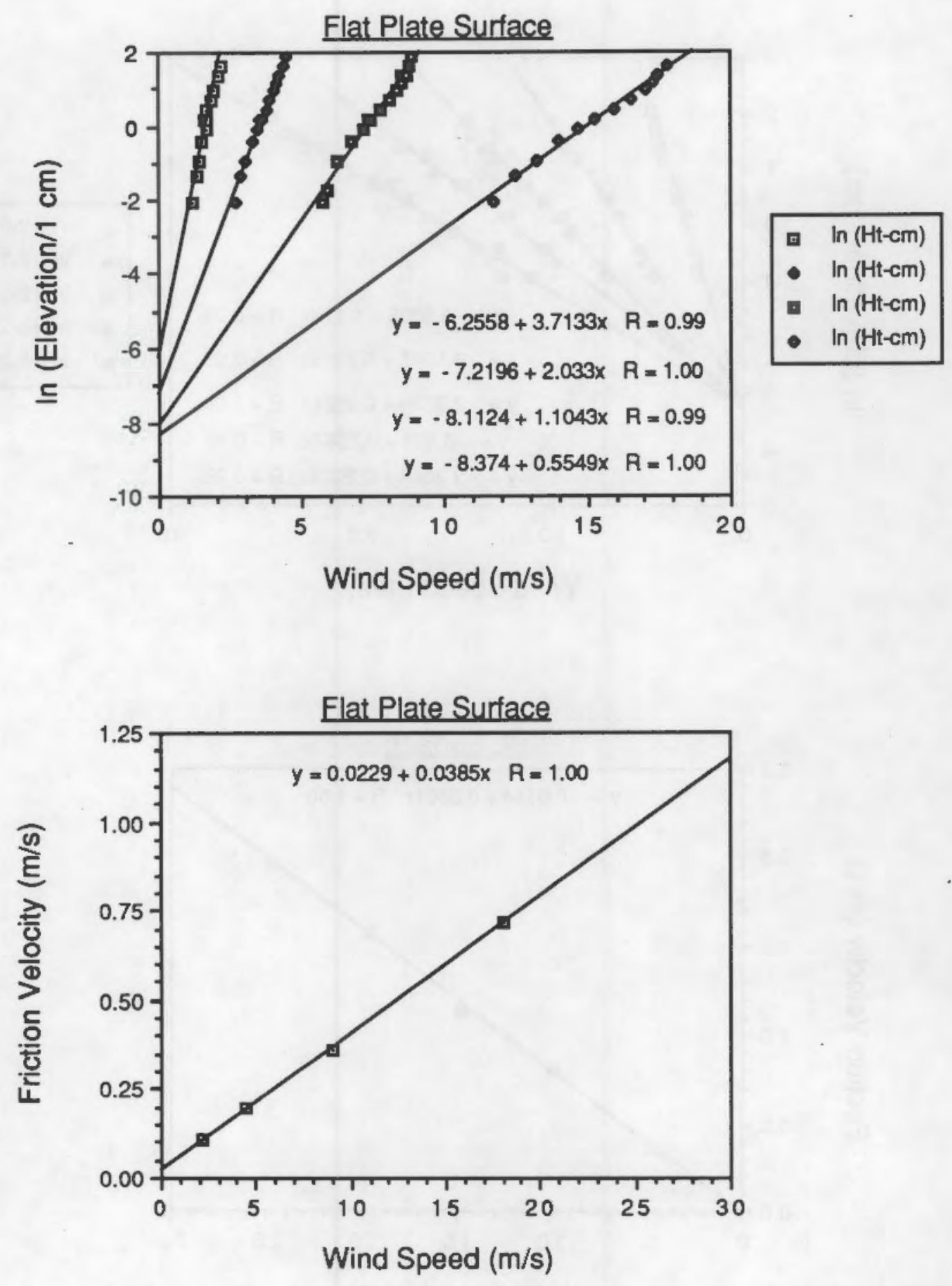

FIGURE 4.5. Boundary Layers over the Aluminum Plate Surface, Plotted for the Determination of Surface Roughness and Friction Velocities. (Friction velocities versus wind tunnel free-stream air velocity are shown in the lower plot.) 

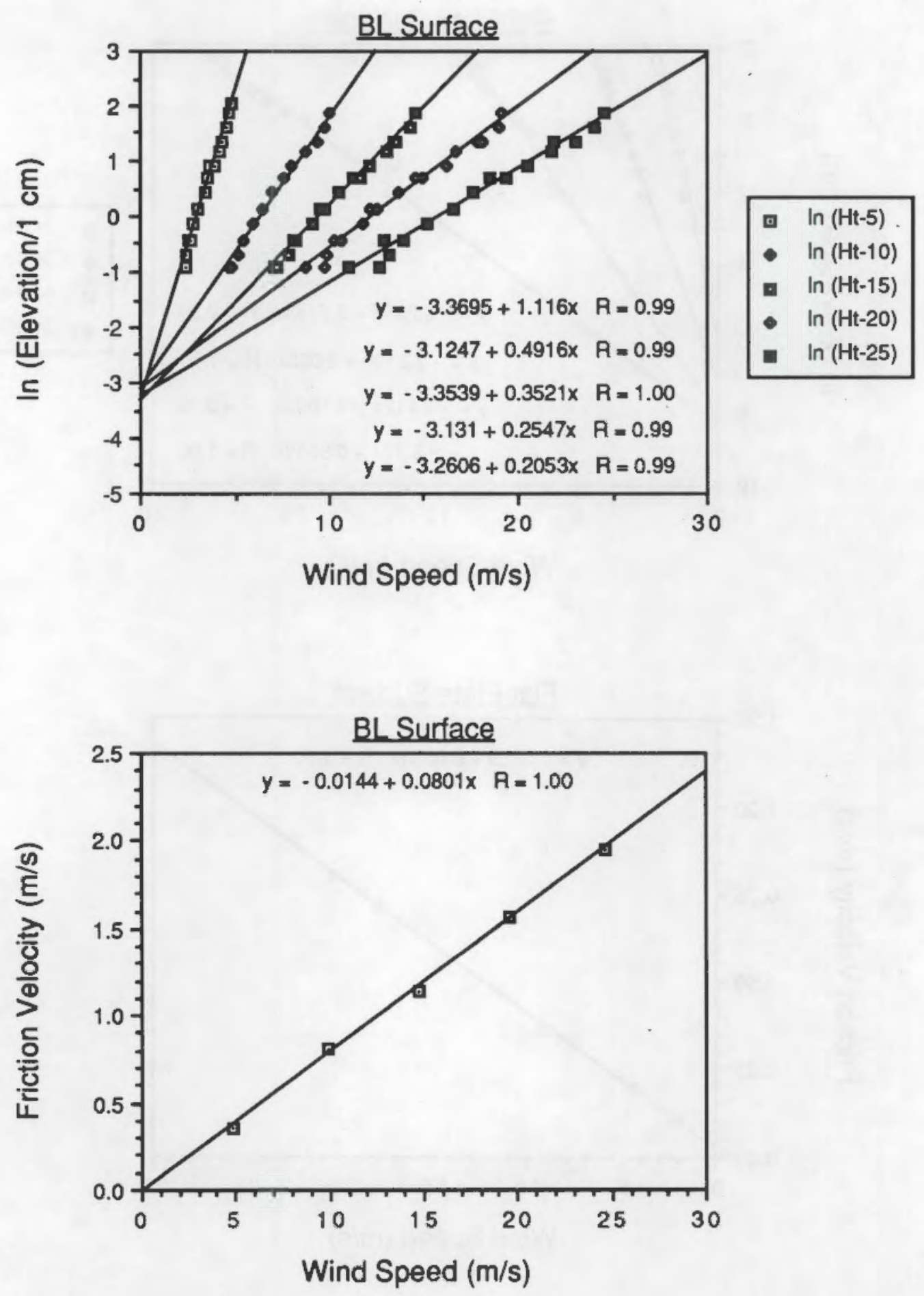

FIGURE 4.6. Boundary Layers over the Fixed Boundary Layer Surface, Plotted for the Determination of Surface Roughness and Friction Velocities. (Friction velocities versus wind tunnel free-stream air velocity are shown in the lower plot.) 


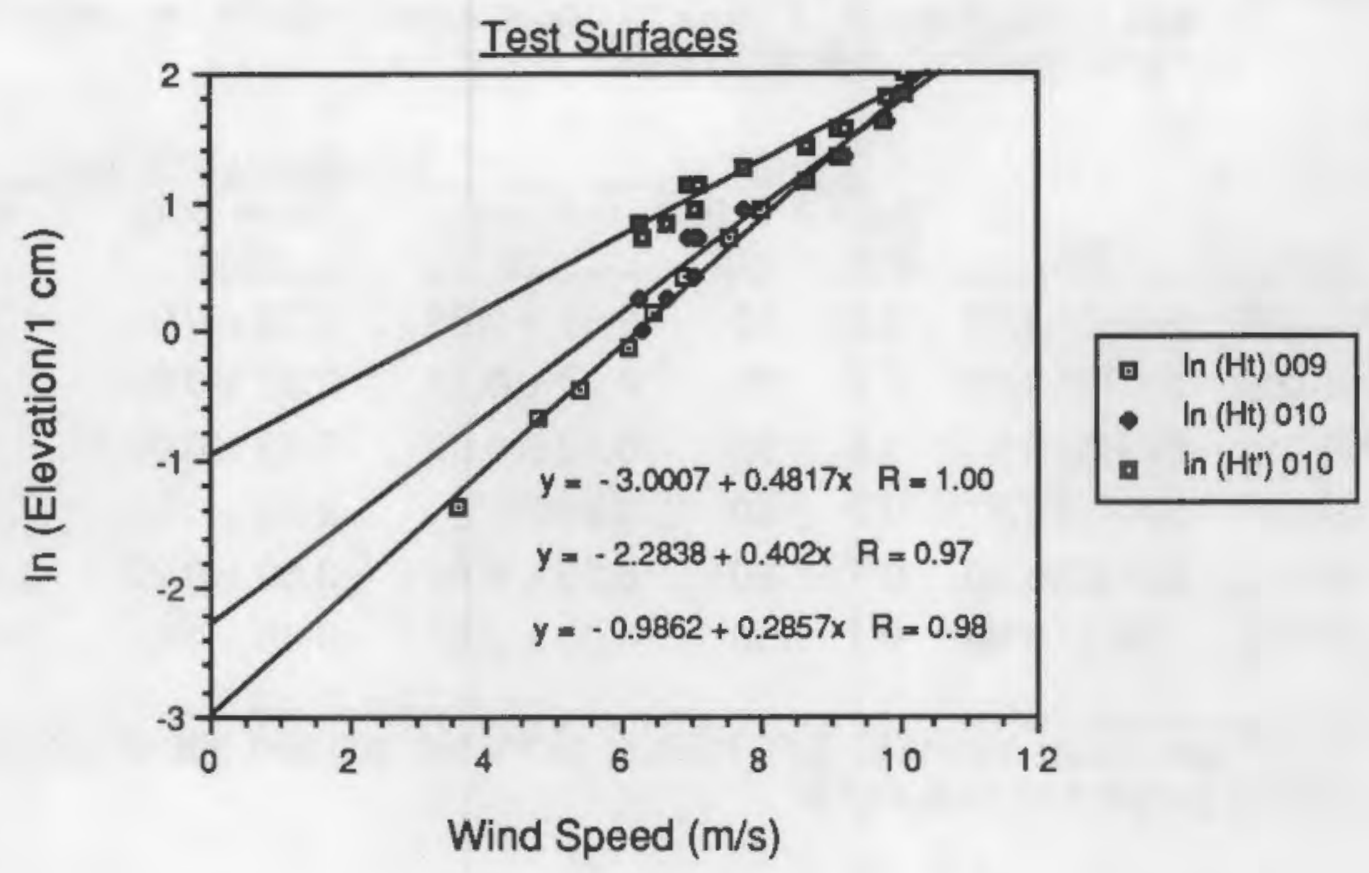

FIGURE 4.7. Boundary Layers over the Test Surface, Plotted for the Determination of Surface Roughness and Friction Velocities. (Friction velocities are dependent on gravel size and surface roughness.)

increased from 0.35 to $2.0 \mathrm{~m} / \mathrm{s}$. Measurements of friction velocity at $10 \mathrm{~m} / \mathrm{s}$ over both $0.7-\mathrm{cm}$ gravel surface types, boundary layer and actual test surface, indicated nearly similar results: $0.81 \mathrm{~m} / \mathrm{s}$ over the boundary layer surface and $0.83 \mathrm{~m} / \mathrm{s}$ over the actual test surface. The single measurement of friction velocity for the $1.6-\mathrm{cm}$ gravel surface was $1.2 \pm 0.2 \mathrm{~m} / \mathrm{s}$ at $10 \mathrm{~m} / \mathrm{s}$. It was estimated that the range of friction velocities over the $1.6-\mathrm{cm}$ gravel surface increased from 0.4 to $3.4 \mathrm{~m} / \mathrm{s}$ for wind speeds of 5 to $25 \mathrm{~m} / \mathrm{s}$.

\subsection{TESTS AND SOIL MOISTURE CONTENT}

Six tests were completed and are described in Table 4.1. Three replicate tests were performed for the $30 \% 0.7-\mathrm{cm}$ gravel surface, two replicate tests of the $50 \%$ $0.7-\mathrm{cm}$ gravel surface, and one test of the $30 \% 1.6-\mathrm{cm}$ gravel. Seven additional trial and surface weathering tests also were performed.

Results of soil moisture content (SMC) measurements are also listed in Table 4.1. All values listed in the table represent actual SMCs; the gravel fraction 
IABLE 4.1 Tests and Initial and Post-Test Soil Moisture Content (percentage of dry soil mass) Results. Tabulated uncertainties include the range of variability of all measurements.

\begin{tabular}{|c|c|c|c|c|c|c|}
\hline \multirow[b]{2}{*}{ Test } & \multirow[b]{2}{*}{ Tray } & \multicolumn{2}{|c|}{ Gravel } & \multicolumn{3}{|c|}{ Soil Moisture Content } \\
\hline & & $\begin{array}{l}\text { Size } \\
(\mathrm{cm})\end{array}$ & $\begin{array}{l}\text { Fraction } \\
(\%)\end{array}$ & $\begin{array}{c}\text { Initial } \\
(\%)\end{array}$ & $\begin{array}{c}\text { Final Bulk } \\
(\%) \\
\end{array}$ & $\begin{array}{c}\text { Final Surface } \\
\frac{(\%)}{(\%)}\end{array}$ \\
\hline BAR-005 & AR87-TR5 & 0.7 & 30 & $2.69 \pm 0.08$ & $2.12 \pm 0.01$ & $1.96 \pm 0.01$ \\
\hline & & 0.7 & 30 & & $.38 \pm$ & .16 \\
\hline BAR-010 & & 1.6 & 30 & 0.121 & $3.69 \pm 0.38$ & $2.18 \pm$ \\
\hline BAR-011 & BAR87-TR7 & 0.7 & 30 & $3.48(a)$ & $2.24 \pm 0.08$ & $2.28 \pm 0.07$ \\
\hline BAR-012 & BAR87-TR8 & 0.7 & 50 & $6.09 \pm 0.66$ & $3.80 \pm 0.23$ & $5.25 \pm 0.96$ \\
\hline BAR-013 & BAR87-TR9 & 0.7 & 50 & $6.09 \pm 0.66$ & $3.86 \pm 0.02$ & $3.67 \pm 0.11$ \\
\hline
\end{tabular}

(a) Tray 7 was made from a $50 / 50 \%$ mixture of the two soil and gravel batches used to prepare trays 5 and 6 .

was removed from each sample after an initial analysis per ASTM (1980) Method D2216-80. As expected, SMCs for the soil and gravel mixture were lower than those reported in the table. The three $30 \% 0.7-\mathrm{cm}$ gravel tests were each performed with slightly varying initial SMCs $(2.7,3.5$, and $4.3 \%)$; however, the post-test analyses indicated less variation. The $50 \% \quad 0.7-\mathrm{cm}$ and $30 \% 1.6-\mathrm{cm}$ gravel surfaces were prepared with substantially greater initial SMCs $(6.1 \%)$. The lower levels of SMC were achieved by air drying the McGee Ranch soil. The higher levels of SMC represented the condition of the McGee Ranch soil after storage for 4 months in sealed steel barrels. Uncertainties in SMC included the range of variability of all measurements, not the standard deviation, because of the limited number of data. Measurements of the surface (the top $1 \mathrm{~cm}$ ) SMC were performed to demonstrate predicted drying of the soil surface during tests. The measurements were inaccurate, however, because some of the samples were obtained about $12 \mathrm{hr}$ after the end of testing. During storage, the surfaces were protected by plastic seals; however, it is likely that the bulk and surface SMCs reached equilibrium before sampling. The reduced surface SMC listed for test BAR-010 may represent a dry surface layer, or may reflect errors in measurement from the presence of large-particle gravel and deeply eroded channels. An increase in the surface SMC after test BAR-012 indicates possible upward migration of SMC about $12 \mathrm{hr}$ post-test. 


\subsection{FLUORESCENT TRACER}

Soil mass collected on the aerosol filters or as losses on the inner walls of the aerosol sampling probe included the fluorescent tracer at a concentration of 1 part tracer to 10,000 parts soil. Selected filter samples were analyzed fluoroscopically, and the results were compared with actual sample soil mass as determined by gravimetric analysis. The calibration, shown in Figure 4.8, revealed that the fluorescent tracer method was useful as an indicator of soil particle mass, but that mass detection resolution was not improved. Calibration against gravimetrically analyzed samples was limited to samples having greater than $0.05 \mathrm{mg}$ of particulate mass; however, analysis by fluoroscopy was also limited to approximately the same sample quantity. Significant scatter in the calibration indicated that inhomogeneities in the tracer-soil mix may have prevented uniform suspension of soil and tracer. It is also possible that the tracer did not suspend consistently with soil mass over the wide range of soil particle sizes. The tracer method could be of increased value during subsequent experiments should it be possible to improve the sensitivity of the fluoroscopic procedure.

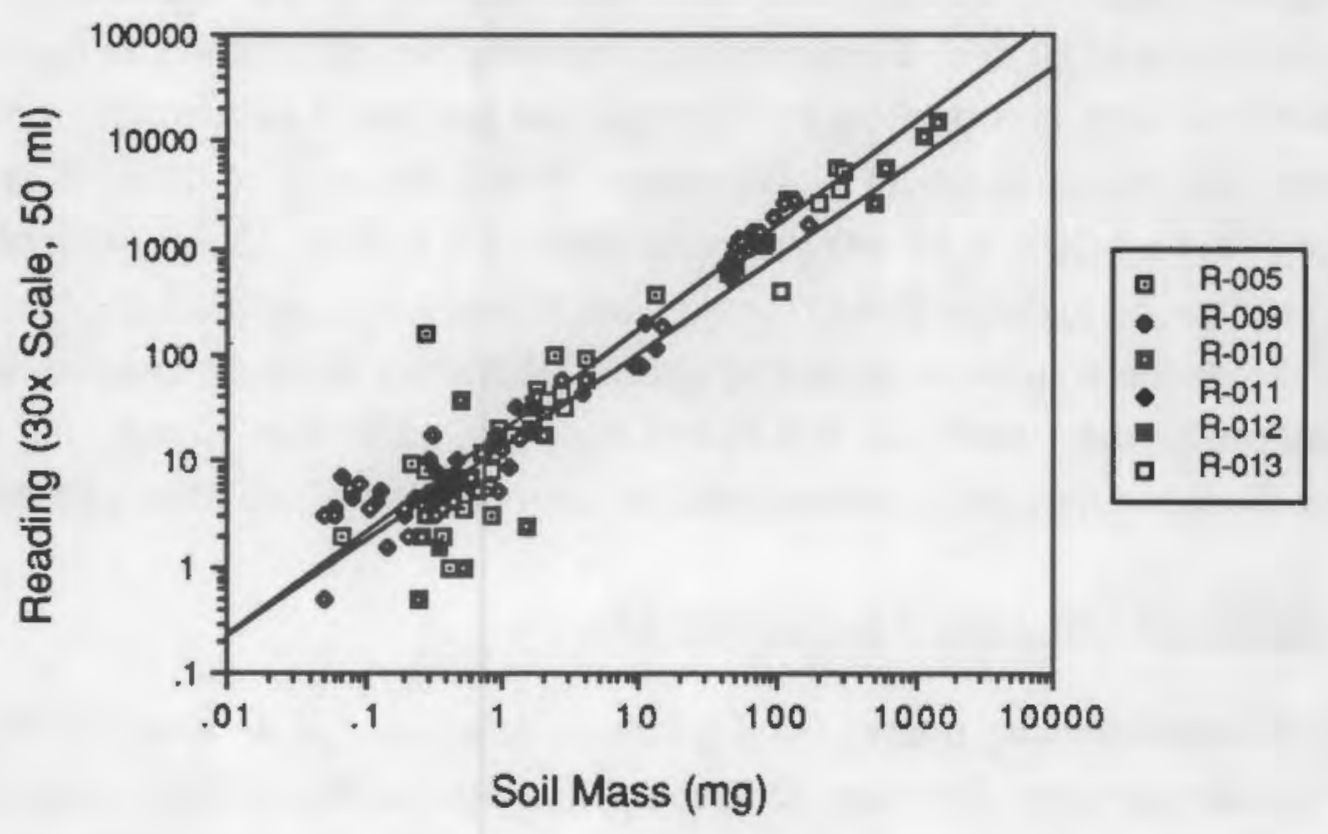

FIGURE 4.8. Calibration of Fluorescent Tracer Versus Mass Collected in Aerosol Samples 


\subsection{SAMPLING PROBE LOSSES}

Knowledge of probe sampling effectiveness, the percentage of each aerosol sample lost by deposition to the inner walls of the sampling nozzle, was important in determining a correction factor to be applied to the gravimetric analysis of aerosol probe filter samples. Two mechanisms were thought to be primarily responsible for sampling probe losses. Because samples were obtained in the turbulent flow of the boundary layer over test surfaces, turbulence would likely bring some particles into contact with sample probe walls. Also, because of the large size of the soil particles suspended and sampled, sedimentation to the bottom of the $10.0-\mathrm{cm}$-long sampling nozzle was likely. Both probe loss mechanisms are influenced by sample flow rate and mean approach wind speed.

Aerosol sampling probe losses were determined by rinsing selected nozzles after sampling and analyzing the resulting solutions fluoroscopically. By comparing them with the fluorometer calibration relationship, a resulting mass of soil lost to the walls of the sampling probe was determined. Probe loss was determined as the ratio of the mass collected in the sample probe divided by the sum of the mass collected in the sample probe and the soil mass collected on the probe's filter. Measurements were repeated twice for samples at a mean wind speed of $5 \mathrm{~m} / \mathrm{s}$, four times at $10 \mathrm{~m} / \mathrm{s}$, and twelve times at $20 \mathrm{~m} / \mathrm{s}$. Correction factors were then determined as the inverse of unity less the probe loss decimal percentage, and applied to all aerosol probe filter data collected at each respective wind speed. Probe losses were $40 \pm 6 \%$ at $5 \mathrm{~m} / \mathrm{s}$ (11 mph), $14.4 \pm 11.9 \%$ at $10 \mathrm{~m} / \mathrm{s}(22 \mathrm{mph})$, and $2.6 \pm 1.5 \%$ at $20 \mathrm{~m} / \mathrm{s}(45 \mathrm{mph})$. The decrease in probe losses with increasing wind speed was attributed to decreased particle residence time in the sampling nozzle. Resultant correction factors applied to all resuspension data were $1.67 \pm 0.16$ at $5 \mathrm{~m} / \mathrm{s}, 1.168 \pm 0.16$ at $10 \mathrm{~m} / \mathrm{s}$, and $1.027 \pm$ 0.016 at $20 \mathrm{~m} / \mathrm{s}$. Uncertainty values include the maximum of the observed data range.

\subsection{PARTICLE CONCENTRATION PROFILES}

Isokinetic sampling probes were generally positioned at an elevation of $1.9 \mathrm{~cm}$ above the test surface. This was done to provide relative information on soil particle suspension for different test surfaces, wind speeds, and exposure durations.

Additional data were obtained, however, at other elevations above the test surfaces. These data were used to determine mass concentration profiles of soil particles 
suspended above the test surfaces. Results of these measurements showed little variation between test surface gravel size and mean wind speed.

Normalized soil particle concentration profiles are shown in Figure 4.9. Vertical uncertainty bars indicate the diameter of the sampling probes, and horizontal uncertainties indicate the range of data obtained from all tests. Only one measurement was obtained at $4.45 \mathrm{~cm}$ and $10 \mathrm{~m} / \mathrm{s}$, and both the magnitude and uncertainty were estimated based on a collected sample of $<0.05 \mathrm{mg}$. Soil particle concentrations were seen to decrease rapidly with increasing elevation over the test surfaces. Profiles measured at 10 and $20 \mathrm{~m} / \mathrm{s}$ were similar with the exception that soil mass concentration increased below $1.9-\mathrm{cm}$ elevations at $20 \mathrm{~m} / \mathrm{s}$, where a roughly blunt concentration profile was observed at $10 \mathrm{~m} / \mathrm{s}$. At $3.8-\mathrm{cm}$ elevation, the elevation corresponding to a velocity equal to approximately $90 \%$ of the free stream velocity, the concentration of soil particles was seen to be about $10 \%$ of that existing near to the surface. These data indicate that $>95 \%$ of the wind-eroded soil mass was transported within $4 \mathrm{~cm}$ of the surfaces. A fifth sampling elevation, $\sim 30 \mathrm{~cm}$ above the test surfaces

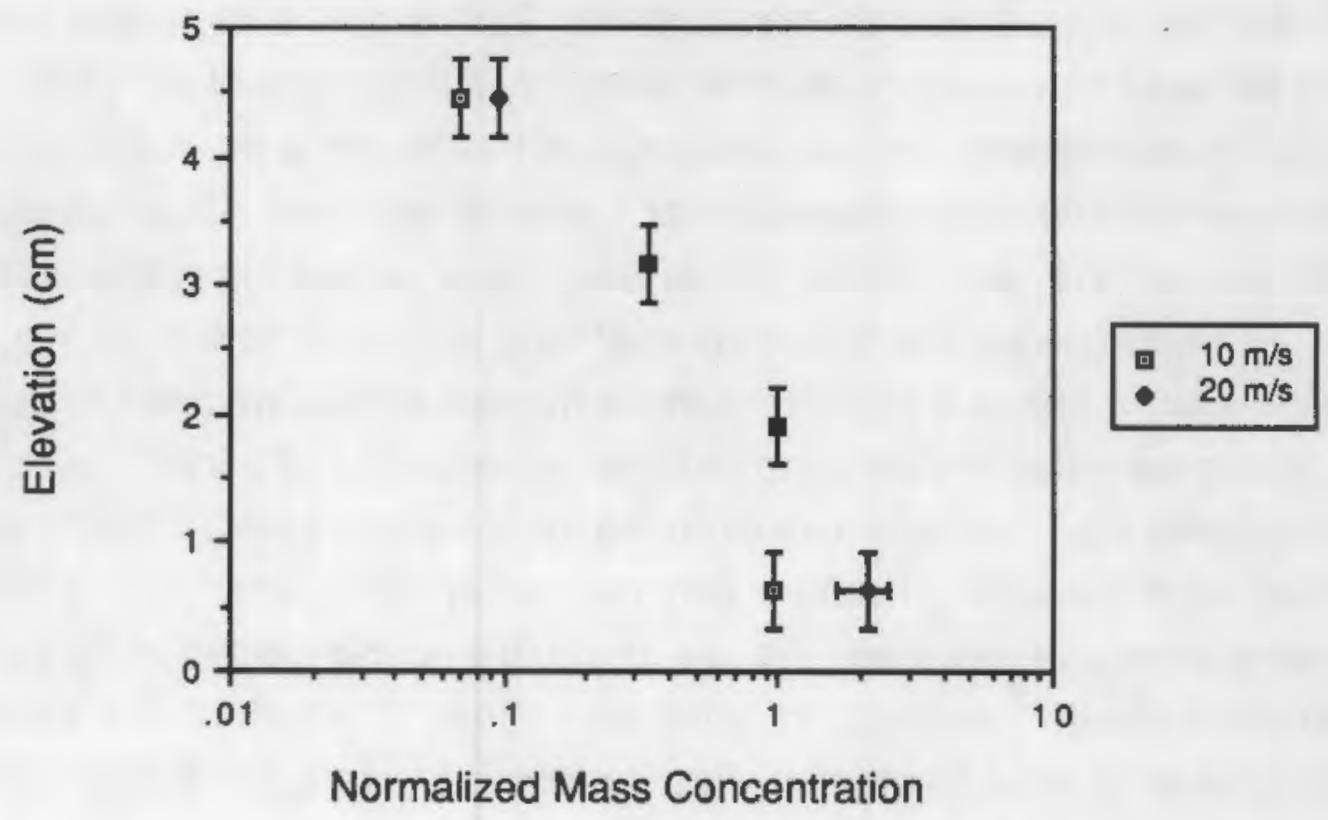

FIGURE 4.9. Normalized Suspended Soil Particle Vertical Concentration Profiles over Test Surfaces at 10 and $20 \mathrm{~m} / \mathrm{s}$ 
was used periodically to measure background particle concentrations; in all cases, data at $30 \mathrm{~cm}$ indicated essentially a zero mass concentration.

The fraction of suspended soil mass that was collected by isokinetic aerosol samplers was determined graphically from the mass concentration profiles. Based on the dimensions of the sampling nozzle and the eroding test surface, each sampling probe was shown to collect $1.97 \%$ of the cross-sectional plume transported at an elevation of $1.9 \mathrm{~cm}$. At a mean wind speed of $10 \mathrm{~m} / \mathrm{s}$, the sampling probe was determined to collect $16 \%$ of the vertical suspended mass concentration profile. At $20 \mathrm{~m} / \mathrm{s}$, the fraction of the vertical mass distribution collected by the sampling probe was $11 \%$, and was less than that at $10 \mathrm{~m} / \mathrm{s}$ because of increased relative mass transport near to the surface. The percentage of the total suspended soil mass collected by each probe was therefore determined to be $0.312 \%$ at $10 \mathrm{~m} / \mathrm{s}$, and $0.219 \%$ at $20 \mathrm{~m} / \mathrm{s}$.

\subsection{MASS BALANCE: AEROSOL SAMPLES VS. ACTUAL SURFACE MASS LOSS}

A comparison was made between mass collected in isokinetic sampling nozzles and the net loss of mass from the test surfaces. This was done to provide a mass balance between total suspended mass determined from aerosol sampling probes and actual mass loss from the test surfaces, and thus to check the suitability of isokinetic samples taken at an elevation of $1.9 \mathrm{~cm}$ to represent actual soil particle suspension over bulk test surfaces. Because of the slow rate of erosion at lower wind speeds, comparisons were only performed at wind speeds of 10 and $20 \mathrm{~m} / \mathrm{s}$. These data are shown in Figure 4.10. Filter sample masses were corrected as described above for losses within the sampling nozzles. Averages of all aerosol samples obtained during each measurement ( 3 during each test at $10 \mathrm{~m} / \mathrm{s}, 2$ during each test at $20 \mathrm{~m} / \mathrm{s}$ ) were considered because they resulted in slightly improved correlation coefficients when compared with the use of a single nozzle located at the centerline of the tray cross section. Isokinetic samples were shown to collect $\sim 0.017 \pm 0.008 \%$ of the total amount of mass lost from the test surfaces at $10 \mathrm{~m} / \mathrm{s}$, and $0.47 \pm 0.13 \%$ of the total mass at $20 \mathrm{~m} / \mathrm{s}$.

Because of the similarity of the normalized mass concentration profiles above the surfaces for both 10 and $20 \mathrm{~m} / \mathrm{s}$, one would expect aerosol probe versus tray (surface) mass loss data to be nearly similar for the two wind speeds. A difference in 


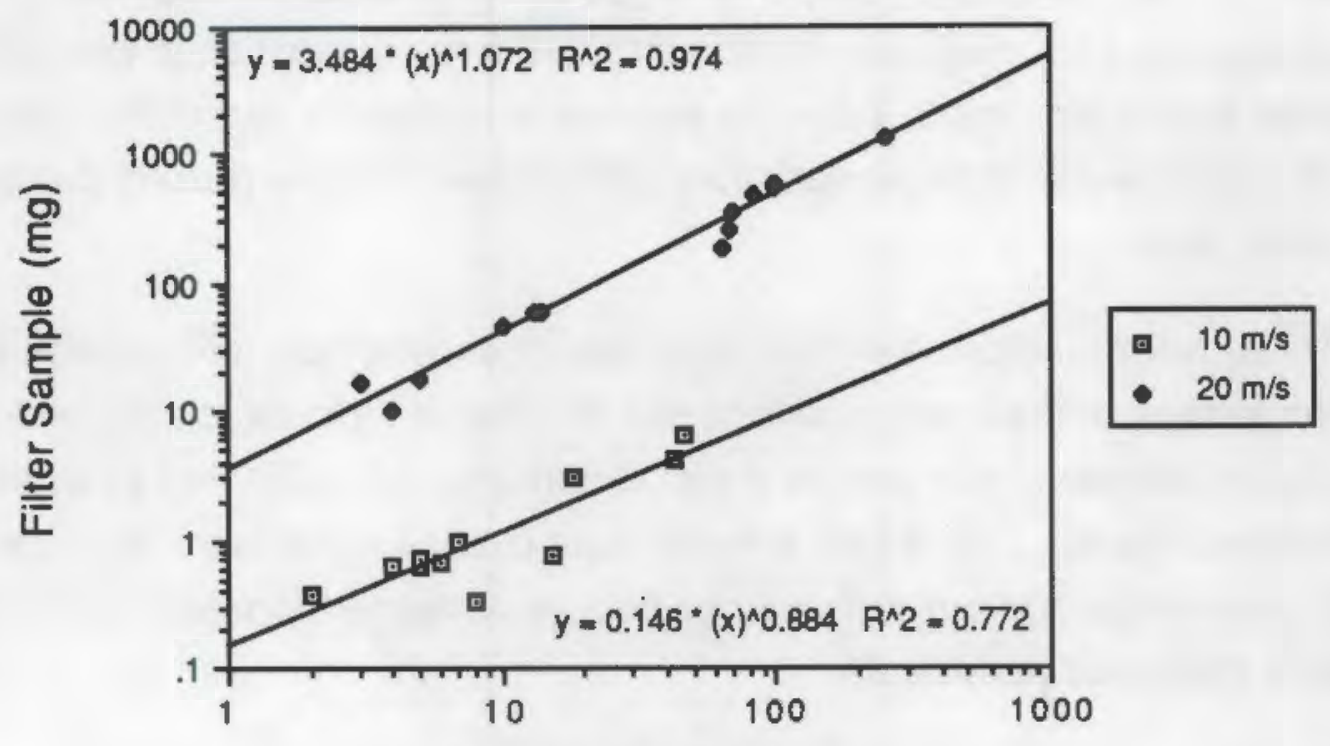

Surface $\Delta$ Mass $(g)$

EIGURE 4.10. Change-in-Mass of Test Surface Versus Mass of Suspended Soil Particles Collected in Isokinetic Aerosol Samples

predicted surface mass loss of 30 to 70 times (or $\sim 50 \mathrm{x}$ ) was actually observed between the two relationships. If such a deviation had been caused by soil particle mass transfer, a greater than observed difference in the vertical particle mass concentration profiles would have been required than was actually seen to be the case. The measured deviation between the two wind speeds was therefore ascribed to differential mass loss from the test surfaces because of evaporation of soil moisture. The possibility of moisture evaporation effects can be used to account for the $\sim 50 \mathrm{x}$ offset between the two sets of data. The exposure duration required to obtain a given test surface mass loss at a wind speed of $10 \mathrm{~m} / \mathrm{s}$ was seen to be approximately $100 x$ greater than the time of exposure at $20 \mathrm{~m} / \mathrm{s}$ required to give the same surface mass loss. This is equivalent to an increase of $100 \mathrm{x}$ in the time available for evaporation of soil moisture. However, the drying potential during exposure of a surface to $10 \mathrm{~m} / \mathrm{s}$ may be approximately one-half of that during exposure to $20 \mathrm{~m} / \mathrm{s}$, based on the $50 \%$ slower transfer rate of air across the surface. When both factors were considered, it was seen that the potential for soil moisture evaporation during tests at $10 \mathrm{~m} / \mathrm{s}$ may have been approximately $50 x$ that during the shorter tests at $20 \mathrm{~m} / \mathrm{s}$. Thus, if soil particle mass loss could be isolated from mass loss because of evaporation of soil 
moisture, it is possible that the two relationships shown on Figure 4.10 would be separated only by the ratio of the percentages of the total suspended mass collected by the nozzles at both wind speeds, or $457 / 321=1.4 x$. In addition to wind-caused differential evaporation rates, it may be possible to attribute a part of the variability in the data to differences in the temperature and relative humidity present during the wind tunnel tests.

These results indicate that the use of one or several isokinetic nozzles at one elevation relative to the eroding surface can be used to indicate relative and absolute rates of wind erosion of soil particle mass as surfaces are weathered by exposure to a constant wind speed. Use of bulk surface mass change to measure absolute soil particle mass deflation from surfaces can also be performed, provided soil moisture content is measured periodically.

\subsection{DEFLATION AND SOILPARTICLE SUSPENSION RATES}

Surface deflation caused by wind erosion of soil particles was measured by exposing test surfaces to constant wind velocities. Deflation was determined both by measuring the actual mass of the test trays and by sampling the suspended soil particle mass above the trailing edge of the trays using sharp-edged isokinetic samplers. Rates of surface deflation were determined for initial and aged surface conditions versus wind speed, aging period, and surface type. Aged surface conditions were defined as those existing after 500 to $1,500 \mathrm{~min}$ of exposure to a steady wind speed. In addition, initial and final SMC did not appear to significantly affect wind erosion over the limited range of SMC tested (2 to $6 \%$ ).

Surface deflation rates determined by both the aerosol filter and tray mass methods are shown in Figure 4.11. Agreement between the two methods was poor at 5 and $10 \mathrm{~m} / \mathrm{s}$, but good at $20 \mathrm{~m} / \mathrm{s}$. As discussed above, the difference between the two methods may be attributed to greater evaporation of SMC during long-duration tests at slow wind speeds. That both methods agree at $20 \mathrm{~m} / \mathrm{s}$ is an indication that the short tests (typically 3 to $15 \mathrm{~min}$ ) at that wind speed, coupled with a greater rate of deflation, prevented evaporation of SMC from impacting the results. The increased rates of deflation predicted by loss of mass from the test trays at $10 \mathrm{~m} / \mathrm{s}$ equaled about $50 x$ more than that measured by isokinetic probe, as predicted above. 

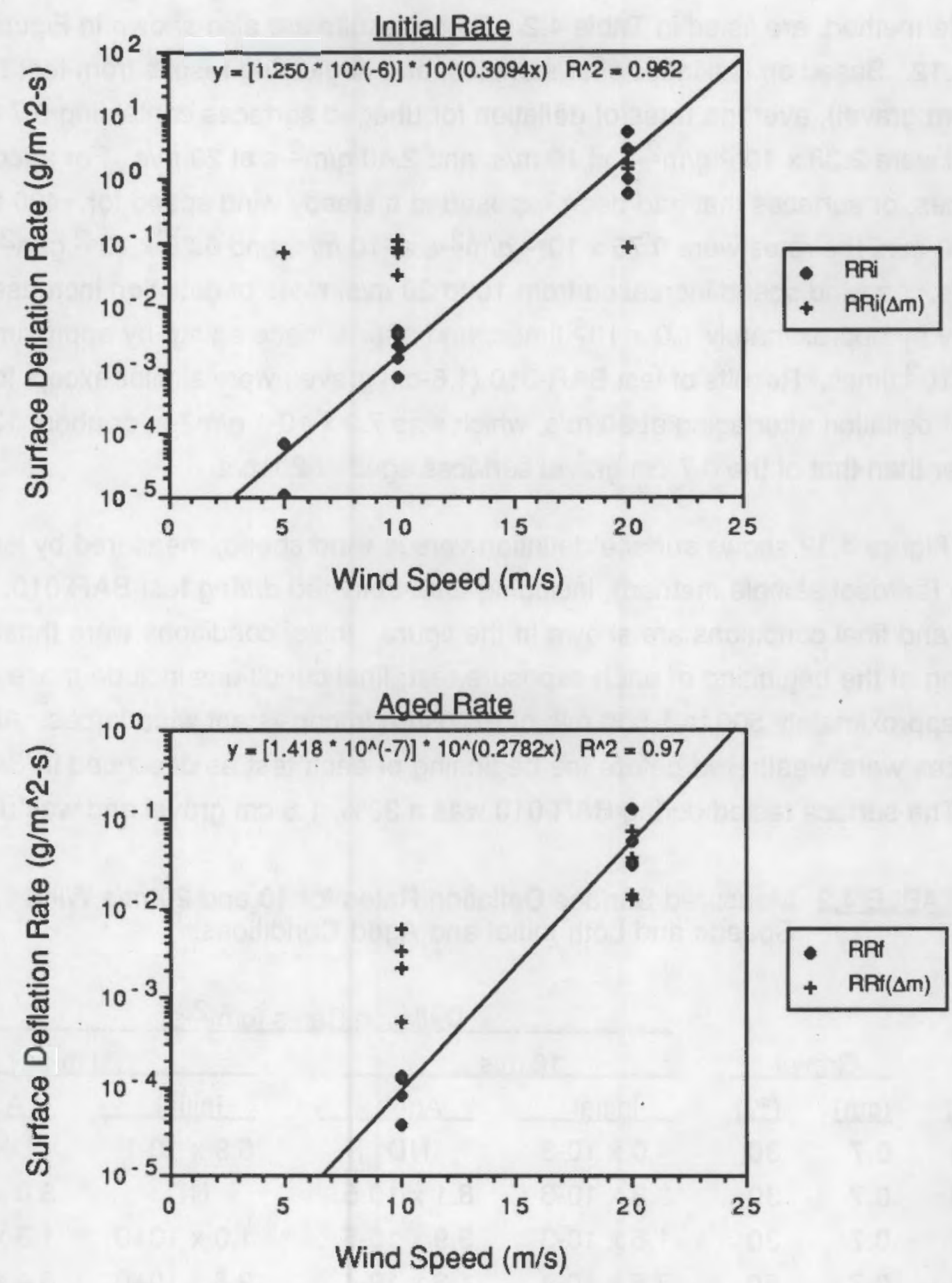

FIGURE 4.11. Rates of Deflation for Weathered Surfaces Initially (i), and After 500 to $1,500 \mathrm{~min}(\mathrm{f})$ Exposure to Steady Wind Speeds of 5,10 , and $20 \mathrm{~m} / \mathrm{s}$ 
A summary of measured surface deflation rates, determined by the aerosol sample method, are listed in Table 4.2. These results are also shown in Figures 4.11 and 4.12. Based on isokinetic filter samples, and neglecting results from test BAR-010 (1.6-cm gravel), average rates of deflation for unaged surfaces containing $0.7-\mathrm{cm}$ gravel were $2.38 \times 10^{-3} \mathrm{~g} / \mathrm{m}^{2}$-s at $10 \mathrm{~m} / \mathrm{s}$, and $2.40 \mathrm{~g} / \mathrm{m}^{2}$-s at $20 \mathrm{~m} / \mathrm{s}$. For aged surfaces, or surfaces that had been exposed to a steady wind speed for $\sim 400$ to $\sim 1,500 \mathrm{~min}$, the rates were $9.75 \times 10^{-5} \mathrm{~g} / \mathrm{m}^{2}$-s at $10 \mathrm{~m} / \mathrm{s}$, and $6.28 \times 10^{-2} \mathrm{~g} / \mathrm{m}^{2}-\mathrm{s}$ at $20 \mathrm{~m} / \mathrm{s}$. As wind speed increased from 10 to $20 \mathrm{~m} / \mathrm{s}$, rates of deflation increased initially by approximately $1.0 \times 10^{3}$ times, and after surface aging, by approximately $6.4 \times 10^{2}$ times. Results of test BAR-010 (1.6- $\mathrm{cm}$ gravel) were similar except for the rate of deflation after aging at $20 \mathrm{~m} / \mathrm{s}$, which was $7.9 \times 10-1 \mathrm{~g} / \mathrm{m} 2-\mathrm{s}$, or about 13 times greater than that of the $0.7-\mathrm{cm}$ gravel surfaces aged at $20 \mathrm{~m} / \mathrm{s}$.

Figure 4.12 shows surface deflation versus wind speed, measured by isokinetic probe (aerosol sample method), including data obtained during test BAR-010. Both initial and final conditions are shown in the figure. Initial conditions were those existing at the beginning of each exposure test; final conditions include those existing after approximately 500 to $1,500 \mathrm{~min}$ of exposure to consistent wind forces. All surfaces were weathered before the beginning of each test as described in Section 3.0. The surface tested during BAR-010 was a $30 \%, 1.6-\mathrm{cm}$ gravel and was unusual

IABLE 4.2 Measured Surface Deflation Rates for 10 and $20 \mathrm{~m} / \mathrm{s}$ Wind Speeds and both Initial and Aged Conditions.

\begin{tabular}{|c|c|c|c|c|c|c|}
\hline \multirow[b]{3}{*}{ Iest } & & & \multicolumn{4}{|c|}{ Deflation Rates $\left(\mathrm{g} / \mathrm{m}^{2}-\mathrm{s}\right)$} \\
\hline & \multicolumn{2}{|c|}{ Gravel } & \multicolumn{2}{|c|}{$10 \mathrm{~m} / \mathrm{s}$} & \multicolumn{2}{|c|}{$20 \mathrm{~m} / \mathrm{s}$} \\
\hline & (cm) & \%) & Initial & Aged & Initial & Aged \\
\hline 005 & 0.7 & 30 & $4.0 \times 10-3$ & ND & $5.9 \times 10-1$ & ND \\
\hline 009 & 0.7 & 30 & $3.3 \times 10-3$ & $8.1 \times 10-5$ & ND & $3.0 \times 10-2$ \\
\hline 011 & 0.7 & 30 & $1.5 \times 10-3$ & $3.9 \times 10-5$ & $1.0 \times 10+0$ & $1.3 \times 10-1$ \\
\hline 012 & 0.7 & 50 & $7.5 \times 10-4$ & $1.3 \times 10-4$ & $2.8 \times 10+0$ & $3.4 \times 10-2$ \\
\hline 013 & 0.7 & 50 & $2.4 \times 10-3$ & $1.4 \times 10-4$ & $5.2 \times 10+0$ & $5.7 \times 10-2$ \\
\hline 010 & 1.6 & 30 & $2.3 \times 10-3$ & $1.2 \times 10-4$ & $3.0 \times 10+0$ & $7.9 \times 10-1$ \\
\hline
\end{tabular}

ND $=$ Not determined. 

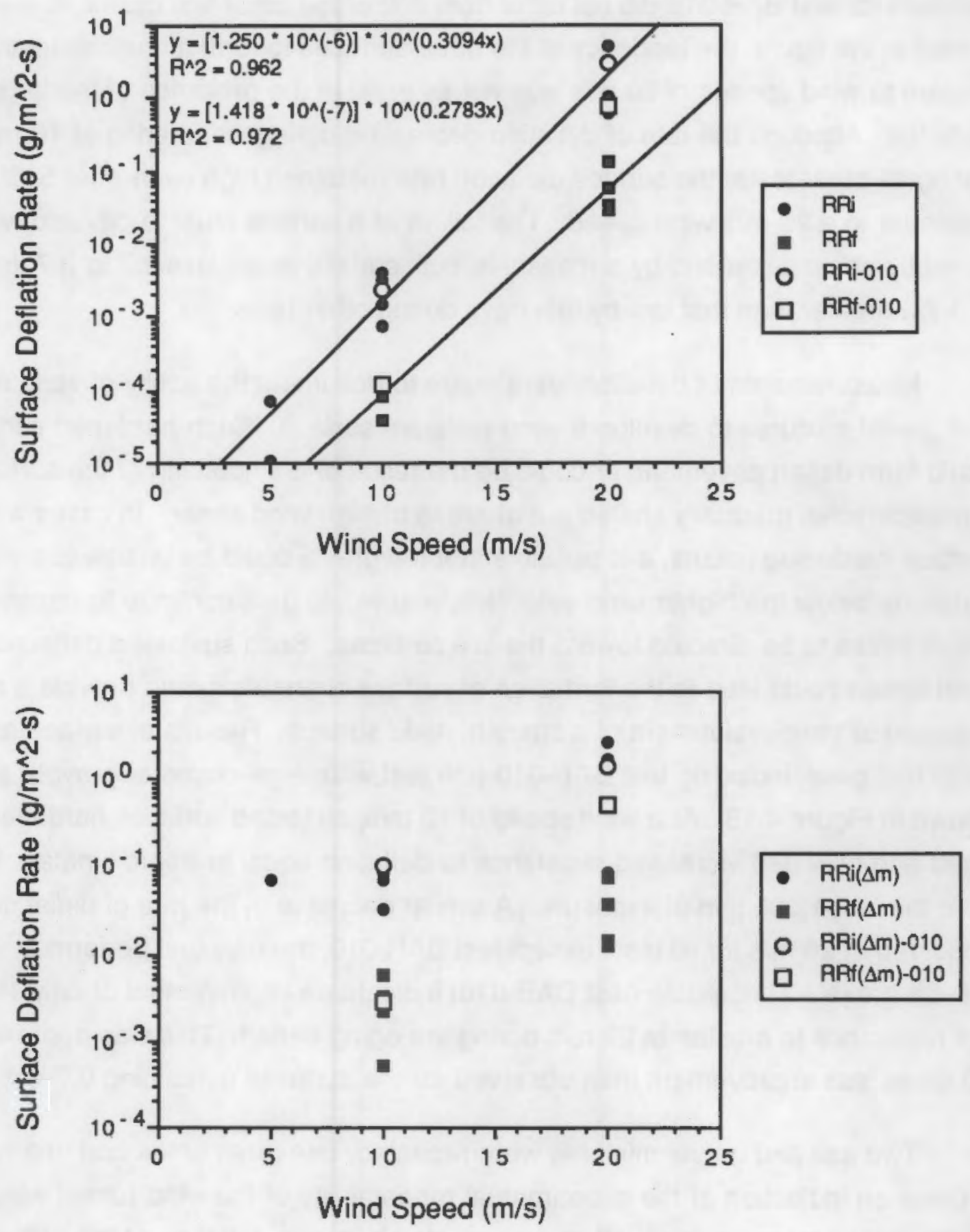

EIGURE 4.12. Rates of Surface Deflation Versus Wind Speed Based on Aerosol (Top Plot) and Bulk Tray Mass (bottom plot) Data. (Bulk tray mass data included evaporation of soil moisture and overpredicted deflation at the lower wind speeds. Initial (i) and end-of-test, or aged (f) conditions shown in both plots.) 
because it was the only case with a gravel size other than $0.7 \mathrm{~cm}$. The initial rate of deflation for test BAR-010 did not differ from that of the other test cases; however, as shown in the figure, the tendency of the other surfaces to form a crust resistant to wind erosion to wind speeds of $20 \mathrm{~m} / \mathrm{s}$ was not as great in the presence of the larger gravel particles. Although the rate of deflation decreased during weathering at $10 \mathrm{~m} / \mathrm{s}$ as during all other tests, the surface deflation rate remained high even after $510 \mathrm{~min}$ of exposure to a $20-\mathrm{m} / \mathrm{s}$ wind speed. The failure of a surface crust to develop was also noted by observation and by a measured bulk surface mass loss 2.7 to 3.7 times (2.7 to $3.7 x$ ) greater than that lost by test trays during other tests.

Measurements of deflation were made to document the ability of various soil and gravel mixtures to develop a wind-resistant surface. Such hardened surfaces could form desert pavement, or could be the result of a smoothing of the surfaces as gravel particles gradually shifted out of areas of high wind shear. In cases when no surface hardening occurs, it is possible that the gravel could be unable to shift to positions below the higher wind velocities, and would thus continue to cause wind shear forces to be directed toward the soil surfaces. Such sustained deflection of wind forces could lead to the formation of surface channeling, and provide a net force opposed to the development of a smooth, aged surface. Results of surface aging of each test case, including test BAR-010 (the test with large-diameter gravel), are shown in Figure 4.13. At a wind speed of $10 \mathrm{~m} / \mathrm{s}$, all tested surfaces hardened as they aged and provided increased resistance to deflation equal to approximately 100 times over the first 1,000 min of exposure. A similar decrease in the rate of deflation was observed at $20 \mathrm{~m} / \mathrm{s}$ for all tests except test BAR-010, the only test performed with 1.6- $\mathrm{cm}$ gravel. These data (test BAR-010) indicate an improvement of only 10 times in the resistance to erosion at $20 \mathrm{~m} / \mathrm{s}$ during the aging period. This was approximately 10 times less improvement than observed for the surfaces containing $0.7-\mathrm{cm}$ gravel.

Two soil and gravel mixtures were repeated, one three times and one twice, to provide an indication of the experimental repeatability of the wind tunnel wind erosion tests. Because no obvious differences existed between deflation of the $30 \% 0.7-\mathrm{cm}$ surfaces and that of the $50 \% 0.7-\mathrm{cm}$ surfaces, all five tests were compared for repeatability. Measurements made at $10 \mathrm{~m} / \mathrm{s}$ were generally less repeatable than those made at $20 \mathrm{~m} / \mathrm{s}$. Variations in surface deflation rates, measured by isokinetic filter samplers, were typically $\pm 1 / 2$ order of magnitude at $10 \mathrm{~m} / \mathrm{s}$ and $\pm 1 / 4$ order of 


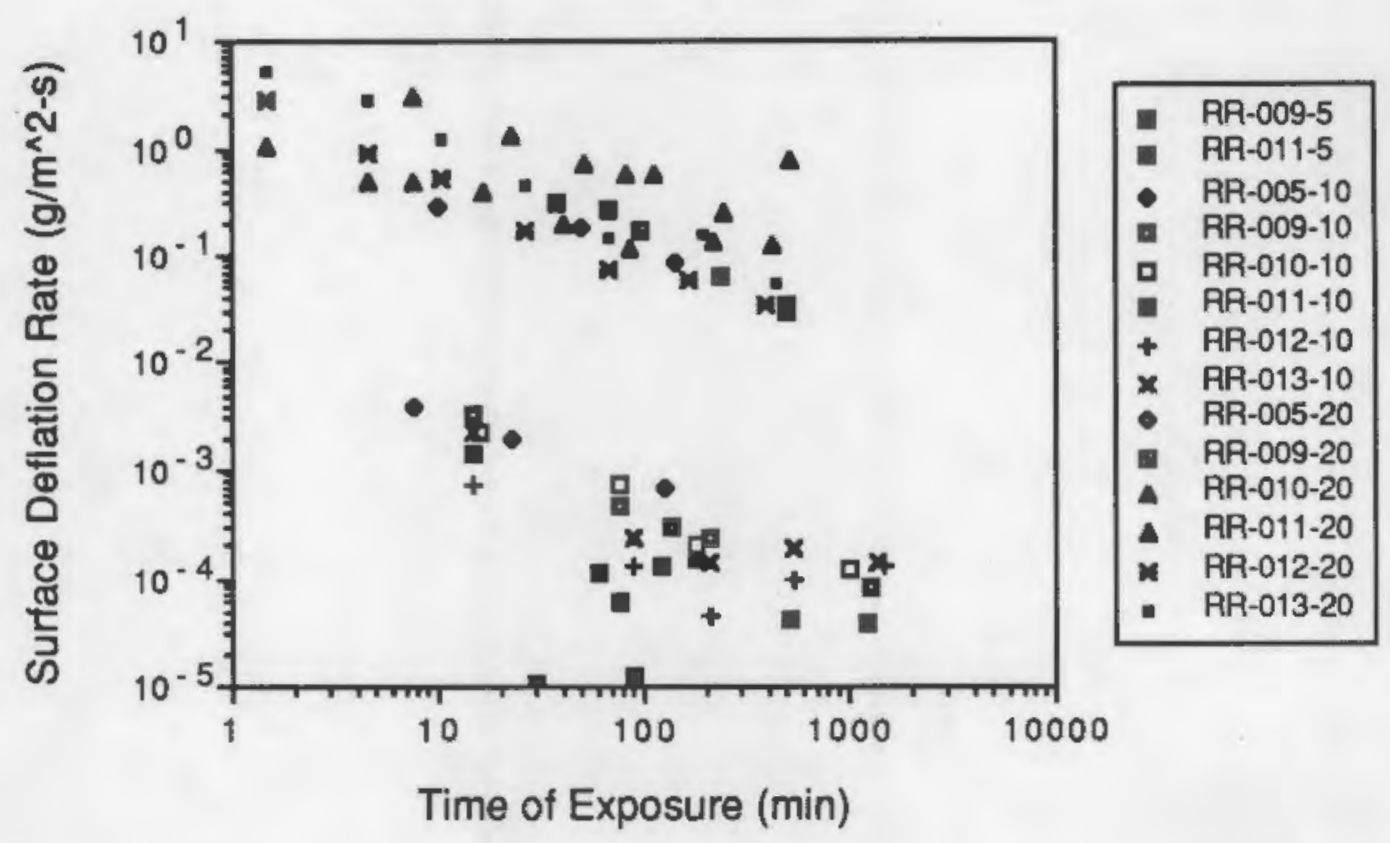

FIGURE 4.13. Surface Deflation Rates Versus Time of Exposure to Steady Wind Speeds of 5,10 , and $20 \mathrm{~m} / \mathrm{s}$. [Translation of figure key: Data type (RR), test number (005, and 009 to 013), and wind speed (5, 10, and $20 \mathrm{~m} / \mathrm{s})]$

magnitude at $20 \mathrm{~m} / \mathrm{s}$. Analysis of the $20 \mathrm{~m} / \mathrm{s}$ data indicated an average coefficient of variance $\left(C V=[\text { standard deviation/mean }]^{*} 100\right)$ of 61.5 (the range was 35 to 86 ). Conditions existing during the experiments that might contribute to the range of repeatability may have included nonuniform soil surface characteristics, nonuniform soil particle concentration profiles, SMC, wind tunnel temperature and relative humidity, storage between tests, or human error. Regardless, because surface deflation measurements were made over a range of six orders of magnitude, these ranges of repeatability in measured surface deflation rates were judged not to be excessive or restrictive when applied to the goal of comparing various surfaces for resistance to wind erosion. 



\subsection{CONCLUSIONS AND RECOMMENDATIONS}

Gravel size influenced surface resistance to wind erosion. Small-particle gravel (0.7-cm modified pea gravel) provided better wind erosion control at wind speeds to $20 \mathrm{~m} / \mathrm{s}(45 \mathrm{mph})$ than did large-particle gravel $(1.6 \mathrm{~cm})$. Hardened, wind-resistant surface crusts developed as soil and gravel mixtures were weathered at a wind speed of $20 \mathrm{~m} / \mathrm{s}$ when $0.7-\mathrm{cm}$ gravel particles were mixed at 30 and $50 \%$, by mass, with McGee Ranch silt-loam soil. These crusts included wind-sculpted soil surfaces and partially buried gravel particles and were similar to, but did not contain as large a percentage of rock cover as desert pavement surfaces found to occur naturally in desert climates. The crusts resulted in a decrease in particle suspension rate of approximately 100 times over a 1000 min aging period which included exposure to a consistent $20 \mathrm{~m} / \mathrm{s}$ wind speed. One test was performed with a $30 \%$ mixture of $1.6-\mathrm{cm}$ gravel and, although a protective crust was formed at a wind speed of $10 \mathrm{~m} / \mathrm{s}$ (22 mph), no crust developed at $20 \mathrm{~m} / \mathrm{s}$. This occurrence was attributed to the large gravel size that was assumed to direct large wind forces toward the surface. This hypothesis was supported by observation that deep (up to $3 \mathrm{~cm}$ ) channels formed in the presence of large gravel particles as the surface was weathered.

Because the results of the current study are preliminary, and are based on only the first of a series of experiments, no definitive surface mixture having optimum wind erosion resistance characteristics can be proposed. Future tests will address additional surface mixture types and allow selection of appropriate surface mixtures. Although using a 30 or $50 \%$ mixture of $0.7-\mathrm{cm}$ gravel was optimum among the limited tests completed in the current study, it is unlikely that this mixture would provide the best protection from wind erosion. One possible disadvantage of the small-particle gravel is the observed tendency for it to saltate at high wind speeds (greater than $20 \mathrm{~m} / \mathrm{s}$ in the wind tunnel). Impact energy of saltating gravel could result in greatly increased deflation during peak wind speed gusts. Stabilizing effects of a vegetative cover must be, in part, discounted because of the expected frequency of range fires, which periodically remove vegetation on the Hanford Site. Stabilizing effects of natural crusts may remain intact following a range fire, but can be disturbed by extreme wind events, animals, or man. A surface mixture that may provide improved resistance to deflation might include a well-graded mixture of gravel mixed with soil. 
Wind tunnel measurements were employed to assess relative surface stability (resistance to wind erosion) using three replicates of one surface mixture and two replicates of another. Because no differences were observed between the surface stability of 30 and $50 \%$ gravel mixtures of $0.7-\mathrm{cm}$ gravel, the number of replicate tests considered was actually five. Measurements of surface deflation rate versus wind speed and duration of exposure (or weathering) indicated a repeatability of approximately $1 / 4$ order of magnitude (or a coefficient of vaniance of 61.5) at a wind speed of $20 \mathrm{~m} / \mathrm{s}$. Because the range of measured surface deflation rates included six orders of magnitude, this repeatability was judged to be adequate.

As noted in Section 2.0, many factors and approaches can be used to compare measurements of wind erosion in the laboratory with those occurring in the field. However, of primary importance are the effects of surface length, induced saltation, and multiple-direction wind forces on erosion processes. Surfaces should be tested that are prepared with other gravel sizes as well as with well-graded mixtures. The influence of turbulence and peak gusts should be addressed by exposure to surface shears comparable with peak gusts, or by mechanical disturbance of wind tunnel flows. Surface characteristics such as plant roots (diffuse and deep root structures), surface crusts, or terrain microrelief such as plants should be considered. Soil moisture content should be controlled and measured during all tests because it will affect soil particle adhesion.

In addition to the continuing wind tunnel experiments of surface configuration and resistance to deflation, additional studies are needed to investigate deposition of wind-bome materiais to the surface of barniers and the potential formation of largescale wind erosion structures. The potential for displacement of surface soil and formation of large eolian structures should be investigated; initial investigations should include completion of an analysis of Hanford Site soils and wind-borne sand transport potential (initiated by Kasper and Glantz), and an analysis of wind patterns over and near proposed barner shapes. In addition to defining the composition of wind resistant surface layers, results of future work may include alteration of the barrier design by modification of the slope of above-surface barrier edges, information on potential effects of locating barriers near certain topographical features on the Hanford Site with respect to sand deposition and sand dune formation, and the potential recommendation of wind break structures to be located upwind or on top of above-surface barners. 


\subsection{REFERENCES}

Adams, M. R., and N. R. Wing. 1986. Protective Barrier and Warning Marker System Development Plan. RHO-RE-PL-35P, Rockwell Hantord Operations, Richland, Washington.

American Society for Testing and Materials (ASTM). 1984. Standard Method for Particle-Size Analysis of Soils. D422-63 (Reapproved 1972), American Society for Testing and Materials, Philadelphia, Pennsylvania.

American Society for Testing and Materials (ASTM). 1980. Standard Method for Laboratory Determination of Water (Moisture) Content of Soil, Rock, and SoilAgaregate Mixtures. D2216-80, American Society for Testing and Materials, Philadelphia, Pennsylvania.

Bagnold, R. A. 1941. The Physics of Blown Sand and Desert Dunes. Methuen and Co. Ltd., London.

Bormann, S., and R. Jaenicke. 1987. "Wind Tunnel Experiments on the Resuspension of Sub-micrometer Particles from a Sand Surface." Atmospheric Environ. 21(9):1891-1898.

Chepil, W. S. 1945a. "Dynamics of Wind Erosion: I. Nature of Movement of Soil by Wind." Soil Sci. 60:305-320.

Chepil, W. S. 1945b. "Dynamics of Wind Erosion: II. Initiation of Soil Movement." Soil Sci. 60:397-411.

Chepil, W. S. 1950. "Properties of Soil Which Influence Wind Erosion: I. The Governing Principle of Surface Roughness." Soil Sci. 69:149-162.

Chepil, W. S., and R. A. Milne. 1941. "Wind Erosion of Soil in Relation to Roughness of Surface." Soil Sci. 52:417-431.

Chepil, W. S., and N. P. Woodrutt. 1963. "The Physics of Wind Erosion and its Control." Advances in Argon, 211:302.

Chepil, W. S., D. V. Armbrust, and F. H. Siddoway. 1964. "Effects of Ridges on Erosion of Soil by Wind." Soil Sci. 28:557-560.

Fairchild, C. I., and M. J. Tillery. 1982. "Wind Tunnel Measurements of the Resuspension of Ideal Particles." Atmospheric Environ. 16:229-238.

Last, G. V., M. A. Glennon, M. A. Young, and G. W. Gee. 1987. Protective Barrier Materials Analysis: Fine Soil Site Characterization. PNL-6314, Pacific Northwest Laboratory, Richland, Washington. 
Ligotke, M. W., D. A. Cataldo, P. Van Voris, and C. A. Novich. 1986. "Analysts use Wind Tunnel to Study Particle Behavior in the Environment." Research and Development, T. M. Kelly, Bamington, Illinois.

Logie, M. 1981. "Wind Tunnel Experiments on Dune Sands." Earth Sunfaces Process and Landforms. 6:365-374.

Logie, M. 1982. "Influence of Roughness Elements and Soil Moisture on the Resistance of Sand to Wind Erosion." In Aridic Soils and Geomornhic Processes, ed. D. H. Yaalon, pp. 161-173.

Myers, D. R. 1985. Disposal Material Study. RHO-WM-EV-12 P, Rockwell Hanford Operations, Richland, Washington.

Nylan, J. W., and L. J. Lane. 1986. Erosion Control Technology: A User's Guide to the Use of the Universal Soil Loss Equation at Waste Burial Facilities [water erosion]. LA-10262-M, Los Alamos National Laboratory, Los Alamos, New Mexico.

Sehmel, G. A. 1984. "Deposition and Resuspension." In Atmospheric Science and Power Production. DOE/TIC-27601, pp. 533-583, National Technical Information Center, Office of Scientific and Technical Information, Oak Ridge, Tennessee.

Sehmel, G. A. 1980. "Particle Resuspension: A Review." Environmental Int. 4:107-122.

U. S. Department of Energy (DOE). 1987a. Interim Hanford Waste Management Plan. U.S. Department of Energy, Washington, D.C.

U. S. Department of Energy (DOE). 1987b. Final Environmental Impact Statement: Disposal of Hanford Defense High-Level. Transuranic. and Tank Waste. DOE/EIS-0113, U.S. Department of Energy, Washington, D.C.

Zingg, A. W. 1949. "A Study of the Movement of Surface Wind." Agriculture Engineering. 30(1):11-13. 


\section{DISTRIBUTION}

No. of

Copies

\section{OFFSITE}

2 DOE Office of Scientific and Technical Information

\section{ONSITE}

8 DOE Richland Operations Office

G. L. Bracken

J. J. Broderick

R. D. Freeburg

R. E. Gerton

R. D. Izatt

G. W. Rosenwald

J. P. Sands

D. M. Smith

\section{Westinghouse Hanford Company}

M. R. Adams

L. C. Brown

J. W. Cammann

R. A. Carlson

H. F. Daugherty

K. A. Gasper

W. F. Heine

J. M. Henderson

G. W. Jackson

K. N. Jordan

D. S. Landeen

R. E. Lerch

H. E. McGuire

K.W. Owens

P. C. Payne

K. L. Petersen

S. J. Phillips

J. F. Relyea

R. C. Roos

R. C. Routson

W. W. Schulz

S. A. Weigman
No. of

Copies

ONSITE (con't)
N. R. Wing
D. D. Wodrich
R. D. Wojtasek
D. E. Wood

41 Pacific Northwest Laboratory

L. L. Cadwell

M. D. Campbell

D. A. Cataldo

J. L. Downs

J. W. Falco

M. J. Fayer

M. G. Foley

H. D. Freeman

G. W. Gee (2)

P. C. Hays

T. L. Jones

C. T. Kincaid

R. R. Kirkham

D. C. Klopier

G. V. Last

M. W. Ligotke (7)

S. O. Link

G. P. O'Connor

W. H. Rickard

L. E. Rogers

R. L. Skaggs

J. A. Stottlemyre

G. P. Streile

J. M. Thomas

R. L. Treat

P. Van Voris

W. J. Waugh

R. E. Wildung

Publishing Coordination

Technical Report Files (5) 


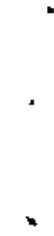

